\title{
Variability and Coherence of the Agulhas Undercurrent in a High-Resolution Ocean General Circulation Model
}

\author{
A. BIASTOCH \\ Leibniz-Institut für Meereswissenschaften, Kiel, Germany \\ L. M. BEAL \\ Rosenstiel School of Marine and Atmospheric Science, Miami, Florida \\ J. R. E. LUTJEHARMS \\ University of Cape Town, Rondebosch, South Africa \\ T. G. D. CASAL \\ Rosenstiel School of Marine and Atmospheric Science, Miami, Florida \\ (Manuscript received 14 November 2008, in final form 30 March 2009)
}

\begin{abstract}
The Agulhas Current system has been analyzed in a nested high-resolution ocean model and compared to observations. The model shows good performance in the western boundary current structure and the transports off the South African coast. This includes the simulation of the northward-flowing Agulhas Undercurrent. It is demonstrated that fluctuations of the Agulhas Current and Undercurrent around 50-70 days are due to Natal pulses and Mozambique eddies propagating downstream. A sensitivity experiment that excludes those upstream perturbations significantly reduces the variability as well as the mean transport of the undercurrent. Although the model simulates undercurrents in the Mozambique Channel and east of Madagascar, there is no direct connection between those and the Agulhas Undercurrent. Virtual float releases demonstrate that topography is effectively blocking the flow toward the north.
\end{abstract}

\section{Introduction}

The Agulhas Current, the major western boundary current of the Southern Hemisphere (Lutjeharms 2006), largely controls the interocean exchange of water, heat, and salt between the Indian and the Atlantic Oceans south of Africa (de Ruijter et al. 1999a). This exchange has been demonstrated (Weijer et al. 1999) to be a major factor controlling the thermohaline overturning of the whole Atlantic Ocean on a time scale of decades (Biastoch et al. 2008b) to centuries. Even on geological time scales the flux of water from the Agulhas system into the Atlantic has shown to be closely related to ice

Corresponding author address: Arne Biastoch, Leibniz-Institut für Meereswissenschaften (IFM-GEOMAR), Düsternbrooker Weg 20, 24105 Kiel, Germany.

E-mail: abiastoch@ifm-geomar.de ages (Peeters et al. 2004). The degree of this interocean leakage may be determined to a substantial degree by the total volume flux of the Agulhas Current proper.

This volume flux has been measured in various ways near $30^{\circ} \mathrm{S}$. By geostrophy alone (Lutjeharms 1972; Jacobs and Georgi 1977), estimates have varied from 56 to $137 \mathrm{~Sv}\left(\mathrm{~Sv} \equiv 10^{6} \mathrm{~m}^{3} \mathrm{~s}^{-1}\right)$. In estimates based on current measurements extrapolated to the seafloor, Gründlingh (1980) indicated the value to be $72 \mathrm{~Sv}$. All these estimates were based on the supposition that the Agulhas Current extended uninterruptedly to the seafloor. Subsequent observations using full-depth, direct velocity measurements and a mooring array (Beal and Bryden 1999; Bryden et al. 2005) have established an average value of $69.7( \pm 21.5)$ Sv over a period of 9 months. This value is lower than a number of others, since these accurate observations established the existence of an Agulhas Undercurrent (Beal and Bryden 1997) carrying 
water upstream relative to the Agulhas Current proper. This undercurrent is found against the continental slope centered at an average depth of about $1200 \mathrm{~m}$, directly below the surface core of the Agulhas Current. It is about $2000 \mathrm{~m}$ deep and $30 \mathrm{~km}$ wide with speeds of order $0.2 \mathrm{~m} \mathrm{~s}^{-1}$. Bryden and Beal (2001) estimated that the undercurrent carries $40 \%$ of the Indian Ocean overturning at $32^{\circ} \mathrm{S}$. This undercurrent is evident in only some models (Skogen 1999), possibly related to the proper grid resolution (Maltrud and McClean 2005). It may be analogous to undercurrents found below other major western boundary currents such as the Gulf Stream (Swallow and Worthington 1961) and the Kuroshio (Worthington and Kawai 1972; Nakamura et al. 2008).

Subsequent to this discovery, undercurrents have also been found in the Mozambique Channel (de Ruijter et al. 2002) and under the southern branch of the East Madagascar Current (Nauw et al. 2008). The regions where these undercurrents have been found are both source regions for the Agulhas Current, leading to speculation on the possible connection between them. It has been surmised with a considerable degree of logic (de Ruijter et al. 2002) that the Mozambique Undercurrent may be a direct continuation of the Agulhas Undercurrent, but a direct connection to the East Madagascar Undercurrent seems unlikely. Large topographic features, such as the Mozambique Plateau $\left(\sim 35^{\circ} \mathrm{E}\right)$ and the Madagascar Ridge $\left(\sim 45^{\circ} \mathrm{E}\right)$, block most of the deep flow between the western boundary current system off South Africa and those in the Mozambique Channel and east of Madagascar. In addition, Beal and Bryden (1997) have indicated that the water in the Agulhas Undercurrent not only consists of North Atlantic Deep Water, but also Antarctic Intermediate Water modified by Red Seawater, which must be flowing south on average. This raises questions about the nature and the continuity of the undercurrent.

Recently, direct velocity measurements at four different latitudes in the Agulhas Current show the presence of an undercurrent from Port Elizabeth $\left(\sim 36^{\circ} \mathrm{S}\right)$ to Port Shepstone $\left(\sim 32^{\circ} \mathrm{S}\right)$ along the South African coast (Casal et al. 2009). Farther north, the bathymetry begins to shoal toward the head of the Natal Valley and here measurements suggest that a weakened undercurrent is still present but that it sits offshore of the Agulhas $\left(\sim 30^{\circ} \mathrm{S}\right)$. In a companion paper, Beal (2009) reports on an 18-month record from a deep moored array that reveals a highly variable undercurrent transport of $4.2 \pm 5.2 \mathrm{~Sv}$. Northeastward velocities over $0.5 \mathrm{~m} \mathrm{~s}^{-1}$ are not uncommon. Transport of North Atlantic Deep Water (NADW, below $2000 \mathrm{~m}$ ) within the undercurrent is $2.3 \pm 3.0 \mathrm{~Sv}$. The dominant variability of the undercurrent is at broadly 60 days, the same periodicity found in the Agulhas Cur- rent by Bryden et al. (2005). This signal corresponds to a well-documented meander mode called a Natal pulse (Lutjeharms and Roberts 1988; de Ruijter et al. 1999b) and shows that these meanders are highly barotropic.

The measurements on which our current knowledge of the Agulhas Undercurrent are based are logistically restricted to rather small temporal and spatial scales and leave us with many unanswered questions. For example, what drives the undercurrent? How do the velocity fields respond to the meander mode (there are no time series measurements that resolve both simultaneously)? What determines the periodicity? Most importantly, is the undercurrent a conduit for deep waters flowing to the undercurrents farther north? Does it play a significant role in the ventilation of the deep Indian Ocean?

In this study we attempt to answer these questions, by analyzing a simulated Agulhas Undercurrent within a model that has demonstrated its good performance in simulating the Agulhas Current system as a whole (Biastoch et al. 2008c). We carefully compare our simulations with the observations of Bryden et al. (2005) and Beal (2009) (section 3) and of Casal et al. (2009) and then expand on their limited datasets by studying the interaction of the western boundary current system with the mesoscale field (section 4) and conducting virtual float experiments (section 5).

\section{Model and data}

\section{a. Model}

A high-resolution model of the Agulhas region is nested in a global coarse-resolution ocean-sea ice model based on the "Nucleus for European Modelling of the Ocean" (NEMO, v.2.3; Madec 2006). The global ORCA version used here is part of a model hierarchy developed by the European DRAKKAR multiscale ocean-modeling project (DRAKKAR Group 2007).

The base model utilizes the ORCA configuration, a tripolar grid (Madec and Imbard 1996), avoiding the North Pole singularity by mapping two poles over Canada and Russia; south of $20^{\circ} \mathrm{N}$ (and therefore in the Agulhas region) it is a Mercator grid. The present configuration uses a quasi-isotropic grid size with a nominal resolution of $12^{\circ}$ (ORCA05); its cell size of $45-50 \mathrm{~km}$ in the Agulhas region is not resolving the mesoscale, simulating just some single, relatively large and unrealistic Agulhas rings. In the vertical 46 levels (with 10 levels in the upper $100 \mathrm{~m}$ and $250-\mathrm{m}$ resolution at deepest levels) are used, whereby the bottom cells are allowed to be partially filled. This improved representation of topographic slopes, in combination with a refined, energyand enstrophy-conserving advection scheme [EEN, an 
adaptation of Arakawa and Hsu (1990)], was found to lead to marked improvements in various circulation features (Barnier et al. 2006). The subgrid-scale mixing parameterizations include a representation of the mixed layer dynamics by a 1.5-level turbulent kinetic energy closure (Blanke and Delecluse 1993) model. Viscosity is discretized for momentum by a bi-Laplacian scheme; diffusion by an isoneutral Laplacian scheme. For tracer advection a total variance dissipation scheme (TVD; Zalesak 1979) is used, which is a second-order, two-step monotonic scheme with moderate numerical diffusion avoiding spurious extremes.

The model is driven at the surface by a consistent dataset [the Coordinated Ocean Reference Experiments (CORE); Large and Yeager 2004], a combination of the National Centers for Environmental PredictionNational Center for Atmospheric Research (NCEPNCAR) atmospheric hindcast (Kalnay et al. 1996) and independent observations [such as satellite products, Tropical Ocean Global Atmosphere (TOGA)/Tropical Atmosphere Ocean (TAO) moorings, and rain climatologies] used to correct and to remove known biases, involving adjustments that remove global imbalances. Turbulent fluxes are computed from bulk formulas, allowing the ocean to feed back on the atmospheric fluxes. Data are prescribed at 6-hourly (wind speed, humidity, and atmospheric temperature), daily (short- and longwave radiation), and monthly (rain and snow) resolutions, with interannual variability over the time range 1958-2004. With the existing CORE dataset ("cnyf/ ciaf_1p0") it was found that a relatively high freshwater supply to the North Atlantic caused a collapse of the meridional overturning current (MOC; Griffies et al. 2009; Biastoch et al. 2008a). After identifying an excess of freshwater in the rain component as being responsible for the artificial drift, the precipitation field was reduced, blending observational values (Béranger et al. 2006) north of $30^{\circ} \mathrm{N}$ with the CORE data ("DFS3" in Brodeau et al. 2007, manuscript submitted to Ocean Modell.). However, since even small errors in the freshwater budget are prone to lead to unacceptable drifts in (uncoupled) global model integrations (Griffies et al. 2009), the common practice has been followed by damping sea surface salinity (SSS) toward monthly mean climatological values with a piston velocity of $50 \mathrm{~m} \times(300 \text { days })^{-1}$ (about 1-month time scale) north of $70^{\circ} \mathrm{N}$ and south of $50^{\circ} \mathrm{S}$. Equatorward of these latitudes (and in the high-resolution nest), a very weak damping (more than 1-yr time scale) was used, leaving the evolution within the Agulhas area almost unaffected.

This ORCA05 DRAKKAR version, but under pure CORE forcing and sometimes with different parameterizations, has been used in a series of large-scale studies, such as the variability of the MOC (Latif et al. 2006; Alvarez-Garcia et al. 2008; Biastoch et al. 2008a) or on the variability of the Pacific subtropical cells (Lübbecke et al. 2008). It has been demonstrated that it simulates the large-scale circulation reasonably well, including the heat- and freshwater-driven components of the meridional overturning.

ORCA05 has been initialized from rest using temperatures and salinities from a global climatology (Conkright et al. 2002; Steele et al. 2001) and integrated over $20 \mathrm{yr}$ using the repeated-year version of the CORE forcing data. After that time all prognostic model fields have been interpolated onto a $1 / 10^{\circ}$ model grid (AG01-R) in the greater Agulhas region $\left(47^{\circ}-7^{\circ} \mathrm{S}, 20^{\circ} \mathrm{W}-70^{\circ} \mathrm{E}\right.$; Fig. 1$)$, a fivefold refinement of the original ORCA05 grid, with an average grid cell of $9.5 \mathrm{~km}$ at $30^{\circ} \mathrm{S}$ now resolving the baroclinic Rossby radius of $30 \mathrm{~km}$ well (Chelton et al. 1998). Apart from some resolution-dependent parameters, which are scaled to give a similar nominal value, the same parameterizations have been used. Then, both base and nested models were integrated over the full period of 1958-2004. For the nesting approach NEMO facilitates the Adaptive Grid Refinement in Fortran (AGRIF; Debreu et al. 2008), coupling both model grids at every baroclinic time step of the base model (2160 s). Thereby, the coarse-resolution grid provides all prognostic data along the boundary of the nest. Then, the nest is integrated for four time steps (each $540 \mathrm{~s}$ ); afterward, its boundary and sea surface height data are averaged onto the coarse-resolution grid points and fed back to the base model where the cycle starts again. Every three time steps the full three-dimensional, baroclinic state vector of the nest is averaged onto the base model grid. The interpolation and averaging between both grids are conservative, so that the mean model fields are maintained during almost the full length of the integration [in contrast to early nesting attempts (Fox and Maskell 1996)]. Due to the effective two-way nesting coupling of the base and nest, the model has been used to demonstrate the effects of the mesoscale variability in the Agulhas regime on the interoceanic transport (Biastoch et al. 2008c) and on the Atlantic meridional overturning circulation (Biastoch et al. 2008b).

To test the influence of mesoscale perturbations in the source regions of the Agulhas Current (e.g., Mozambique eddies), a sensitivity experiment (AG01-S) has been performed that limits the northernmost extension of the high-resolution nest at $26^{\circ} \mathrm{S}$, leaving the Mozambique Channel and the Indian Ocean east of Madagascar at the base model resolution and therefore without mesoscale eddies. Biastoch et al. (2008c) have shown that this configuration effectively prevents the generation of 


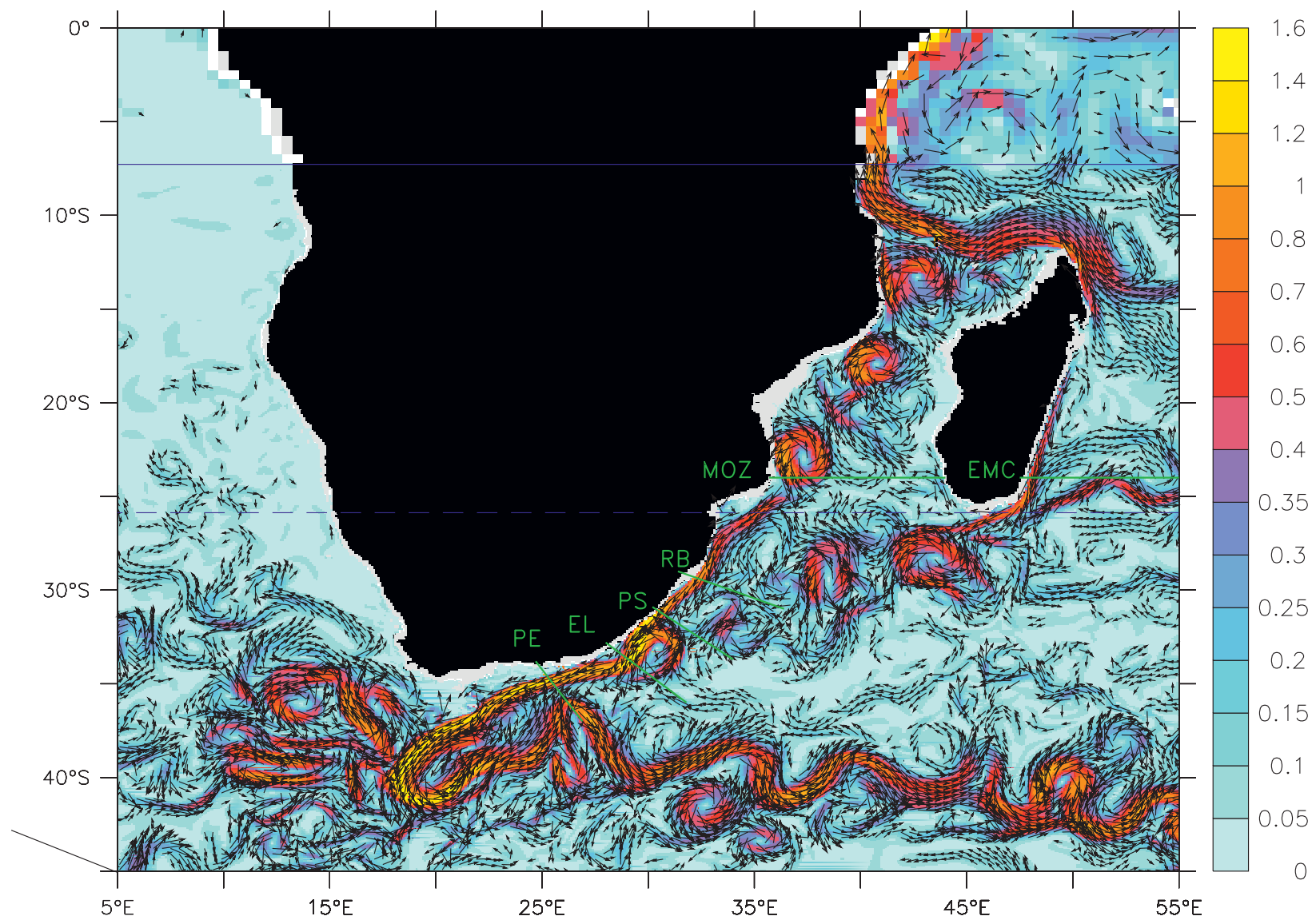

FIG. 1. Speed (color, $\mathrm{m} \mathrm{s}^{-1}$ ) and velocity (every fourth vector shown) at 100-m depth as a 5-day average centered around 21 May 1997. The green lines mark the angled sections shown in Fig. 2 [off Richards Bay (RB), Port Shepstone (PS), East London (EL), and Port Elizabeth (PE)] and Fig. 9 [Mozambique Channel (MOZ) and the East Madagascar Current (EMC)]; the solid blue line marks the northernmost tension of the high-resolution nest (AG01-R), and the dashed blue those of the sensitivity experiment (AG01-S).

Natal pulses and upstream retroflections of the Agulhas Current. Those perturbations do not alter the average interoceanic exchange but lead to more realistic Agulhas rings, with a better spread in dimensions and ring paths in the South Atlantic. Here, we use this experiment to test the influence of Mozambique eddies and Natal pulses on the variability of the Agulhas Current and Undercurrent velocity fields and transports.

To establish a possible coherence of the Agulhas Undercurrent downstream (i.e., into the Mozambique Channel and into the southern branch of the East Madagascar Current regime), an offline Lagrangian diagnostic (ARIANE, information online at http://www. univ-brest.fr/lpo/ariane; Blanke et al. 1999) was used. Typically $O\left(10^{5}-10^{6}\right)$ virtual floats, each representing a small amount (maximum of $10^{-2} \mathrm{~Sv}$ in this case) of water, were seeded in the undercurrent at $32^{\circ} \mathrm{S}$ (which was defined by its direction and a density criterion of $\left.\sigma_{1}=32.30\right)$. The float software advects the individual floats using 5-day velocity means from the model. The algorithm uses all velocity components and analytically calculates a three-dimensional streamfunction for any given time step, thereby avoiding spurious diffusion. The particles were counted when crossing different control sections (Figs. 11-13) and summed (using their individual transports) to give a transport number in sverdrups. Individual analyses have been performed for different release sections and times, control sections, and integration lengths (Tables 2-4). In all cases the particles were continuously seeded over an extended period (typically 7-10 yr) to capture the temporal variability and to provide robust statistics over many instances of mesoscale perturbations (e.g., Natal pulses). To examine the potential limitations due to the 5-day resolution of the advection velocity in the highly variable western boundary current regime off Africa, we have performed a comparison with daily averages for one particular model year. A float advection using the coarser time resolution resulted in transport differences of around $5 \%$ and did not alter any of our conclusions. 


\section{b. Data}

To verify the model's performance with respect to simulating a realistic Agulhas Current and Undercurrent and to complement the model analysis, appropriate observational data have been used in this study.

Two time series of moored array data are available off Port Shepstone at around $32^{\circ} \mathrm{S}$, the site of most of the historic Agulhas measurements (Gründlingh 1980; Donohue et al. 2000). The first is a 9-month record of Agulhas Current velocities and transport collected in 1995 (Bryden et al. 2005) as part of the World Ocean Circulation Experiment (WOCE). The array consisted of five moorings covering a $150-\mathrm{km}$-long section oriented perpendicular to the continental slope. The shallowest instruments were placed at 400-m depth and the deepest were placed at $2000 \mathrm{~m}$, with acoustic current meters profiling the upper ocean on the two inshore moorings. Data were interpolated and linearly extrapolated onto a $1 \mathrm{~km} \times 20 \mathrm{~m}$ grid covering a region from the surface to $2400-\mathrm{m}$ depth and from the coast to $200 \mathrm{~km}$ offshore. For more details of the gap-filling approach and the extrapolation techniques, see Bryden et al. (2005). Because the array was designed without knowledge of an undercurrent, only one current meter, $32 \mathrm{~km}$ offshore and at 2000-m depth, captured northeastward velocities in the mean. We revisit this dataset to calculate Agulhas Current and Undercurrent transports using different integration boundaries in order to make comparisons with the model.

The second time series consists of only two deep moorings, deployed within the undercurrent in 2003 as part of the Agulhas Undercurrent Experiment (AUCE; Beal 2009). Five instruments give an 18-month record of undercurrent transport and North Atlantic Deep Water transport within the undercurrent, from March 2003 to August 2004. For a detailed description of how transport time series were constructed from these measurements, see Beal (2009). In short, data were again gridded and transports were integrated over a static area, defined as the "envelope" between the mean position of the zero isotach separating the undercurrent from the Agulhas, and the continental slope. This envelope was determined by the average of seven direct velocity occupations, as described in more detail below. Although one can argue that the undercurrent changes size and shape over time (when defined as northeastward flow), an integration over constant area was determined to be the most robust method of estimating the transport given the limited coverage of the deep array. It is also consistent with the method used for calculating the Agulhas transport (i.e., fixed area) used by Bryden et al. (2005). NADW transport is defined as the transport within the envelope and below $2000 \mathrm{~m}$.
Several well-resolved snapshots of the Agulhas velocity field are also available for validation of the model. These were collected using high pressure rated, acoustic Doppler current profilers lowered through the water column on a CTD package. During AUCE in March 2003, four cross-stream velocity sections were occupied at different latitudes in the Agulhas Current (Casal et al. 2009; Casal 2008), nominally at $30^{\circ} \mathrm{S}$ (Richards Bay), $32^{\circ} \mathrm{S}$ (Port Shepstone), $34^{\circ} \mathrm{S}$ (East London), and $36^{\circ} \mathrm{S}$ (Port Elizabeth).

In total, seven full-depth, direct velocity sections of the Agulhas Current at the historic $32^{\circ} \mathrm{S}$ section have been collected. From these a composite mean flow field is produced to compare to the mean flow field from the model at this latitude. There have been seven occupations since 1995: 1) the Agulhas Current Experiment (ACE; April 1995), 2) I5W (June 1995), 3) the ACE Recovery (March 1996), 4) I5 Repeat (March 2002), 5) AUCE (February 2003), 6) AUCE 2 (March 2003), and 7) AUCE Recovery (March 2005). ACE Recovery was only a 100-km-long section to 2000-m depth. The last two occupations, AUCE 2 and AUCE Recovery, were fulldepth, 50-km-long sections covering only the undercurrent. All sections are illustrated in Beal (2009) (Fig. 1). The ACE data have been previously published by Beal and Bryden (1997) and Beal and Bryden (1999). The ACE and I5W Agulhas velocity sections were analyzed by Donohue et al. (2000), together with a sparse National Oceanic and Atmospheric Administration (NOAA) occupation also from 1995, which we do not use here. AUCE data have appeared in Beal et al. (2006) and Casal (2008). The composite section was produced by gridding all seven occupations and then averaging over the data at each grid point, ignoring missing data. The transport of the mean Agulhas Current is $68.8 \mathrm{~Sv}$ and that of the undercurrent is $2.5 \mathrm{~Sv}$. Its velocity field is shown later (Fig. 3).

\section{Comparing modeled and observed characteristics of the Agulhas Current and Undercurrent}

How does the model compare to what is known about the greater Agulhas system and to the observations described above? Figure 1 provides a first qualitative picture of the general performance of the simulated flow: consistent with observations throughout the region (Lutjeharms 2006), the trajectory of the Agulhas Current closely follows the African shelf, with current speeds of more than $1.5 \mathrm{~m} \mathrm{~s}^{-1}$. After intruding some $100 \mathrm{~km}$ into the South Atlantic, it retroflects and flows back into the Indian Ocean as a strongly meandering Agulhas Return Current. Anticyclonic (Agulhas rings) and cyclonic vortices, shed at the retroflection, transport warm and salty water into the South Atlantic, which 


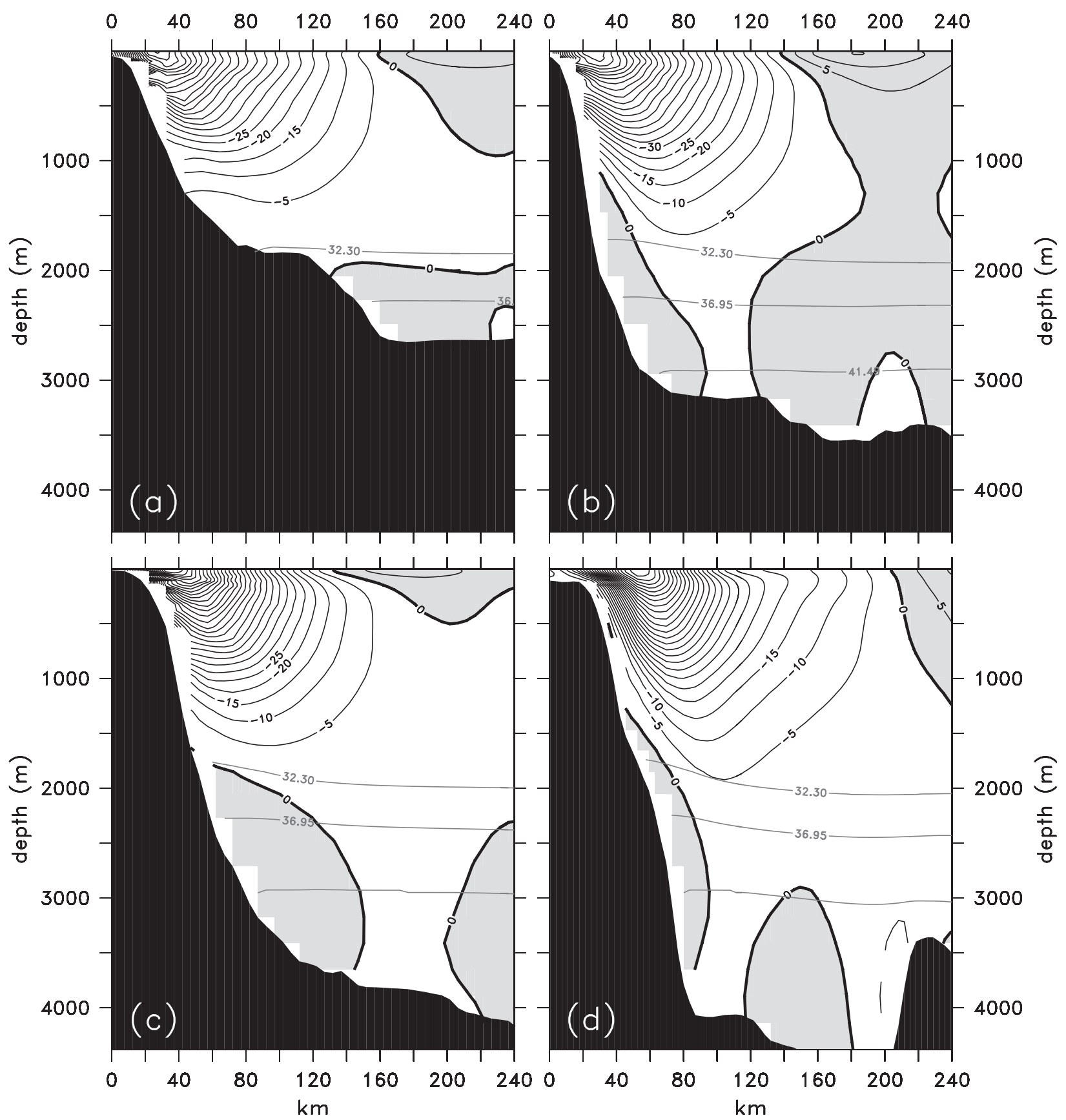

FIG. 2. Sections in the Agulhas Current from north to south: off (a) Richards Bay, (b) Port Shepstone, (c) East London, and (d) Port Elizabeth, showing the velocity in $\mathrm{cm} \mathrm{s}^{-1}$ (northeastward velocities are shaded gray). Data are averaged over the period 1995-2004. Also shown are isopycnals marking the upper bounds of UNADW $\left(\sigma_{1}=32.30\right)$, mNADW $\left(\sigma_{2}=36.95\right)$, and INADW $\left(\sigma_{3}=41.49\right)$.

subsequently affects the Atlantic meridional overturning circulation (Biastoch et al. 2008b). Mesoscale perturbations, seen as eddies in the Mozambique Channel (Schouten et al. 2002) and east of Madagascar (Siedler et al. 2009), drift toward the Agulhas Current, introducing offshore meanders into the core of the current, Natal pulses (Lutjeharms and Roberts 1988). These Natal pulses rapidly propagate southward along the current, causing upstream retroflections (Lutjeharms and van Ballegooyen 1988) and triggering (van Leeuwen et al. 2000) the shedding and thus the characteristics of Agulhas rings (Biastoch et al. 2008c).

Figure 2 demonstrates the modeled western boundary current structure off the African coast at four different 


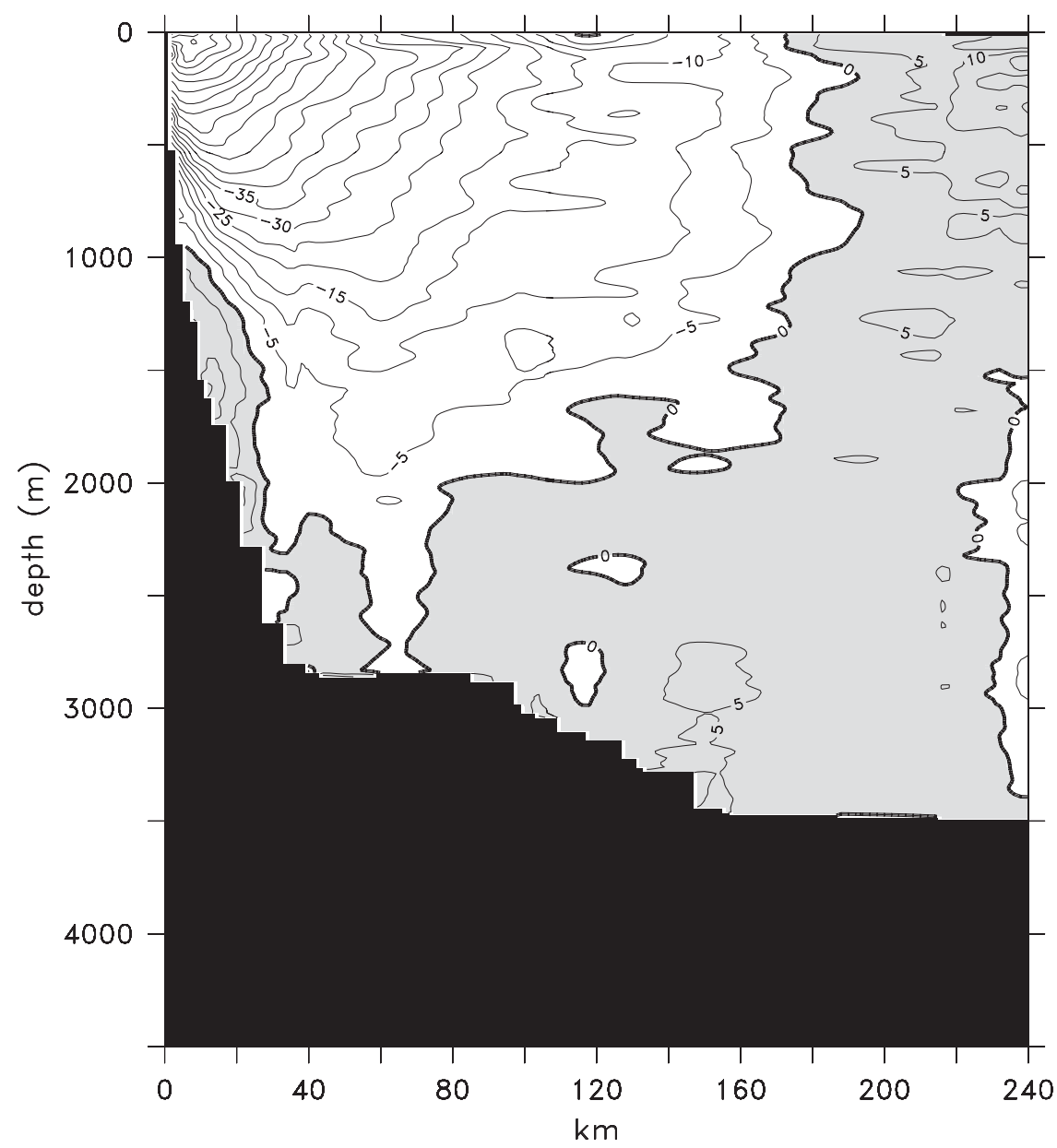

FIG. 3. As in Fig. 2, but for a composite of seven observations off Port Shepstone.

latitudes, corresponding to the positions of the one-time velocity sections occupied as part of AUCE. All simulated sections are oriented cross stream, as were the observations. At $30^{\circ} \mathrm{S}$ (Richards Bay; Fig. 2a) the Agulhas Current is already fully developed, covering the upper $1400 \mathrm{~m}$ and extending $150 \mathrm{~km}$ offshore (defined by the $5 \mathrm{~cm} \mathrm{~s}^{-1}$ isotach). Its width, depth, and maximum velocities agree remarkably well with the observational snapshot (Casal et al. 2009, their Fig. 6a). At $32^{\circ} \mathrm{S}$ (the historic section at Port Shepstone; Fig. 2b) the mean simulated structure shows an Agulhas Current reaching $1700 \mathrm{~m}$. The mean observed structure, which is shown in Fig. 3, has a similar width of 160-180 km, including the v-shape penetration. Notice also that both the simulated and observed velocity fields show a subtle subsurface maximum to the flow. Farther downstream at $34^{\circ} \mathrm{S}$ (East London; Fig. 2c), the strength, width, and depth of the simulated current are again very similar, when compared to a onetime snapshot (Casal et al. 2009, their Fig. 6c). Finally, at $36^{\circ} \mathrm{S}$ (Port Elizabeth; Fig. 2d) the flow is strongest and deepest as reflected in both the simulation and observa- tions, although the AUCE snapshot shows a narrower, deeper structure, with a width $75 \mathrm{~km}$ less and the $10 \mathrm{~cm} \mathrm{~s}^{-1}$ isotach reaching $1000 \mathrm{~m}$ deeper than in the model.

With regard to the Agulhas Undercurrent, snapshots from AUCE show an undercurrent at all latitudes except the most northerly $\left(30^{\circ} \mathrm{S}\right)$, where the continental slope is shallower and broader. Here, there is an indication of a core of deep northward flow offshore of the Agulhas Current instead (Casal et al. 2009, their Fig. 6). Again, the observations are mirrored closely by the model: a weak but persistent undercurrent is seen in all sections. Moreover, comparing the simulated $32^{\circ} \mathrm{S} \mathrm{sec-}$ tion to our composite mean (Fig. 3) shows that the position as well as the size of the undercurrent are well modeled: it extends from $1000 \mathrm{~m}$ to the foot of the slope, with a width of about $30 \mathrm{~km}$. However, core speeds of $15 \mathrm{~cm} \mathrm{~s}^{-1}$ are observed, while the simulation shows speeds of less than $5 \mathrm{~cm} \mathrm{~s}^{-1}$. Figure 2 also illustrates three isopycnals depicting upper (below $\sigma_{1}=32.30$ ), lower (below $\sigma_{2}=36.95$ ), and the core $\left(\sigma_{3}=41.49\right.$ ) of the NADW in this region (Arhan et al. 2003; Beal et al. 

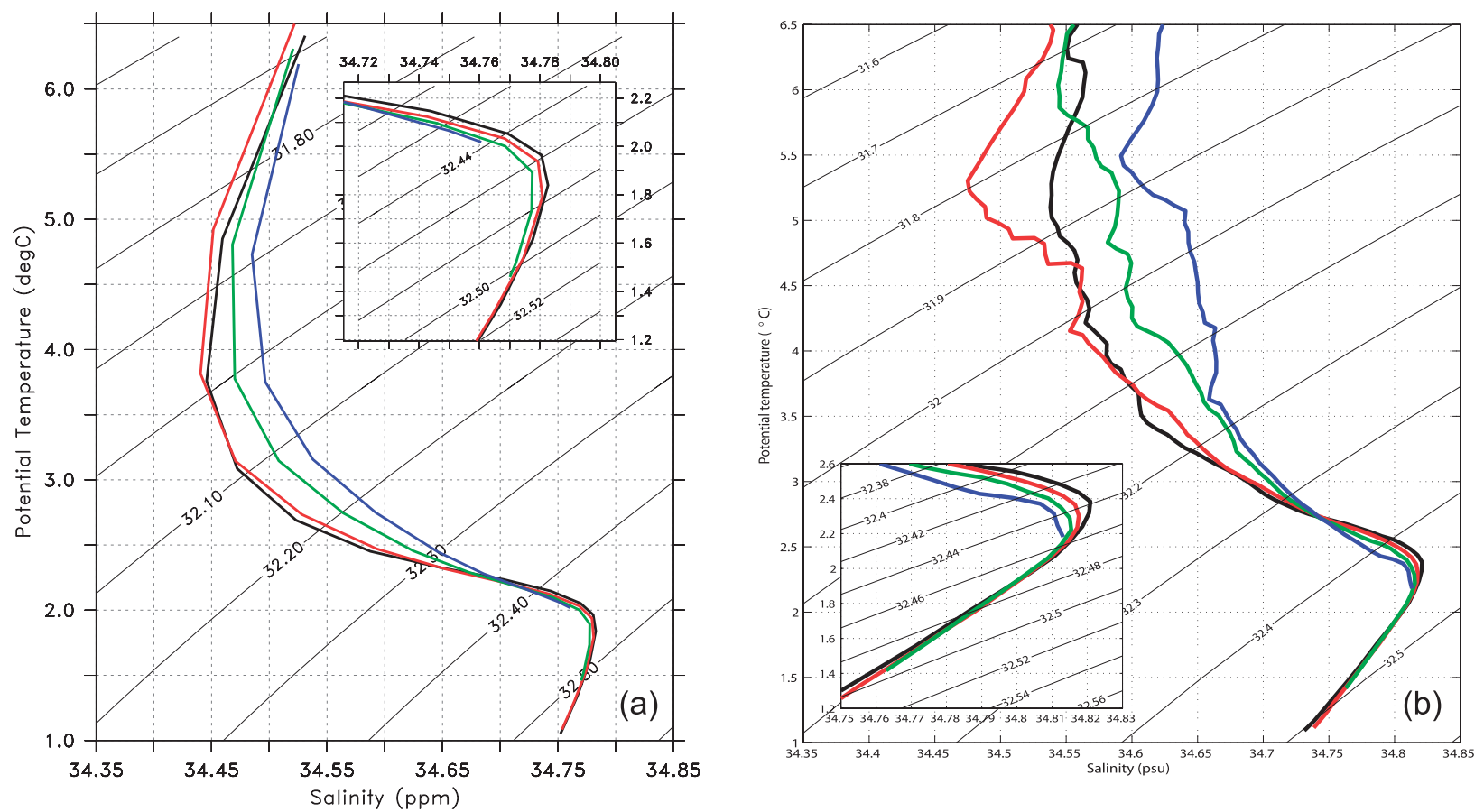

FIG. 4. Average temperature-salinity diagrams within the first $200 \mathrm{~km}$ off the coast at sections off Port Elizabeth (black), East London (red), Port Shepstone (green), and Richards Bay (blue) for the (a) model and (b) observations. Density lines display $\sigma_{1}$. The inlets show a blow-up of the NADW range.

2006). It is clear that the transport of lower NADW within the undercurrent is gradually cut off from south to north by the shoaling bathymetry.

How does the model do in terms of water masses and mixing within the Agulhas Current and Undercurrent? Temperature-salinity diagrams for waters below about $1000 \mathrm{~m}$ are shown in Fig. 4 from (a) the model and (b) the observations. The model has fresher (by 0.05-0.1 psu) water masses compared to the observations (Beal et al. 2006) but indicates a similar erosion of Red Seawater properties from north to south within the Agulhas
Current along $\sigma_{1}=32.00$ (Roman and Lutjeharms 2007), and a freshening of NADW within the undercurrent from south to north along $\sigma_{1}=32.45$. The cutoff of the core of NADW toward the north is also clear here, as we saw in Fig. 2.

Table 1 compares the statistics of simulated transport numbers for the Agulhas Current and Undercurrent at the historic $32^{\circ} \mathrm{S}$ section with revisited estimates from the 1995 mooring array (Bryden et al. 2005). There is a good overall performance of the model in both the mean values and standard deviations (boldfaced values in Table 1).

TABLE 1. Transport calculations of model velocities (Sv) off Port Shepstone in comparison with revisited Bryden et al. (2005) data. Northward velocities are calculated over the complete section (205 km for observations), integrated below $1000 \mathrm{~m}$ or over the first $100 \mathrm{~km}$ ("inshore"); the AUC is defined within the first $100 \mathrm{~km}$ and below $1000 \mathrm{~m}$. Southward velocities are calculated over the complete section or above $2400 \mathrm{~m}$. For accuracy reasons and since the core of the Agulhas Current crosses at $31^{\circ} \mathrm{S}$, model transports are taken at that latitude and calculated over the last $10 \mathrm{yr}$ or covering the same period as the observations (5 Mar-26 Nov 1995). Standard deviations for both observations and the model are calculated based on 5-day averages. Boldface numbers refer to Fig. 5.

\begin{tabular}{|c|c|c|c|c|}
\hline & \multicolumn{2}{|c|}{ AG01-R } & \multirow{2}{*}{$\frac{\text { AG01-S }}{1 \text { Jan 1995-31 Dec } 2004}$} & \multirow{2}{*}{$\frac{\text { Bryden et al. }}{5 \text { Mar-26 Nov } 1995}$} \\
\hline & 3 May-26 Nov 1995 & 1 Jan 1995-31 Dec 2004 & & \\
\hline Northward transport & $7.0 \pm 4.9$ & $9.5 \pm 7.9$ & $3.9 \pm 2.9$ & $9.8 \pm 7.1$ \\
\hline Below $1000 \mathrm{~m}$ & $4.7 \pm 2.7$ & $5.4 \pm 3.7$ & $2.4 \pm 1.6$ & $5.9 \pm 3.6$ \\
\hline Inshore & $2.5 \pm 1.9$ & $2.9 \pm 3.4$ & $1.4 \pm 1.2$ & $3.5 \pm 3.6$ \\
\hline AUC & $2.5 \pm 1.9$ & $2.7 \pm 2.6$ & $1.4 \pm 1.2$ & $2.9 \pm 2.1$ \\
\hline $\mathrm{AC}$ all & $-74.7 \pm 7.1$ & $-78.8 \pm 13.9$ & $-71.4 \pm 7.9$ & \\
\hline AC above $2400 \mathrm{~m}$ & $-73.3 \pm 7.2$ & $-77.3 \pm 13.7$ & $-70.7 \pm 7.8$ & $-78.6 \pm 19.7$ \\
\hline
\end{tabular}




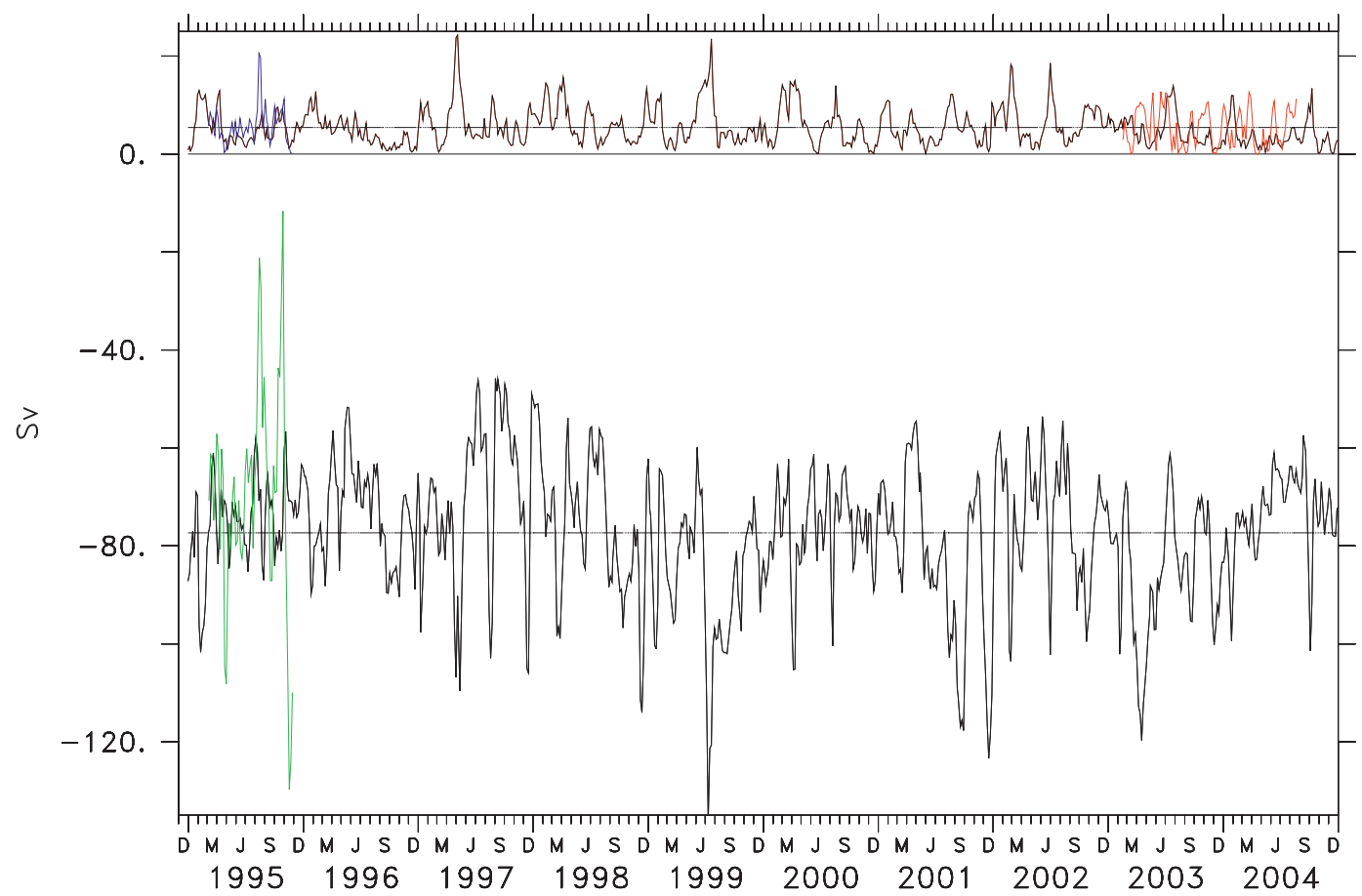

FIG. 5. Transport time series (Sv, 5-day resolution) for the Agulhas Current (negative values) and Undercurrent (positive values). Velocities are integrated at $31^{\circ} \mathrm{S}$; integration boundaries follow Table 1, second row for the Agulhas Undercurrent and sixth row for the Agulhas Current. The dashed lines show the mean values. Shown in red are the observational values of the northward transport of the AUCE moorings (Beal 2009). Green (blue) lines show Agulhas Current (Undercurrent) transports of Bryden et al. (2005). Note that all observations are 5-day averages.

Interestingly, the model suggests that 1995 saw lower Agulhas transports than the long-term mean. A number of reasonable definitions are considered for Agulhas Undercurrent transport: (i) all northward flow across the section, (ii) northward flow below $1000 \mathrm{~m}$, (iii) northward flow inshore of the Agulhas, and (iv) northward flow inshore and below $1000 \mathrm{~m}$. This last definition will give results consistent with the AUCE undercurrent transport time series. We see in Table 1 that the simulated inshore portion of the undercurrent is weaker than observed and that a direct comparison between time frames does not match. This is not surprising considering the different timings of the individual Natal pulses in the model and the observations due to the nonlinear nature of the flow.

In Fig. 5 we show transport time series of the Agulhas Current and Undercurrent at $32^{\circ} \mathrm{S}$, compared to results from the model. The 2004 undercurrent time series is from Beal (2009), while the 1995 Agulhas Current and Undercurrent time series are from Bryden et al. (2005). Again, an exact match cannot be expected, considering the different timings of the individual Natal pulses in the model and the observations. However, peak to peak fluctuations of the Agulhas Current-ranging from a maximal southward transport of more than $120 \mathrm{~Sv}$ to a minimal transport of around $40 \mathrm{~Sv}$-in the model are similar to the observed variability. The Agulhas Undercurrent in turn has maxima of more than $20 \mathrm{~Sv}$ as well as periods with no northward flow. Only the 1995 observational time series shows an extreme event such as the simulated peaks in 1997 or 1999. The standard deviation for the Agulhas Undercurrent compares well with the model observations (Table 1), while the one of the Agulhas Current is too low. However, since the modeled year 1995 has only half of the standard deviation compared to the long-term average, this implies that other years exist with significantly enhanced variability. One can easily find other years with standard deviations of $20 \mathrm{~Sv}$, which is above the observational estimate. All transport time series exhibit significant variabilities around 70 days, which is related to the welldocumented existence of Natal pulses (Lutjeharms and Roberts 1988; de Ruijter et al. 1999b). Natal pulses are also the cause for the dominant variability in the undercurrent, indicating that they are highly barotropic in nature (Beal 2009; Lutjeharms et al. 2001). There is an active interplay between the Mozambique eddies and the Natal pulses, and Biastoch et al. (2008c) have shown that about five to six modeled Mozambique eddies per year trigger two to five Natal pulses (both are referred to as upstream perturbations). 


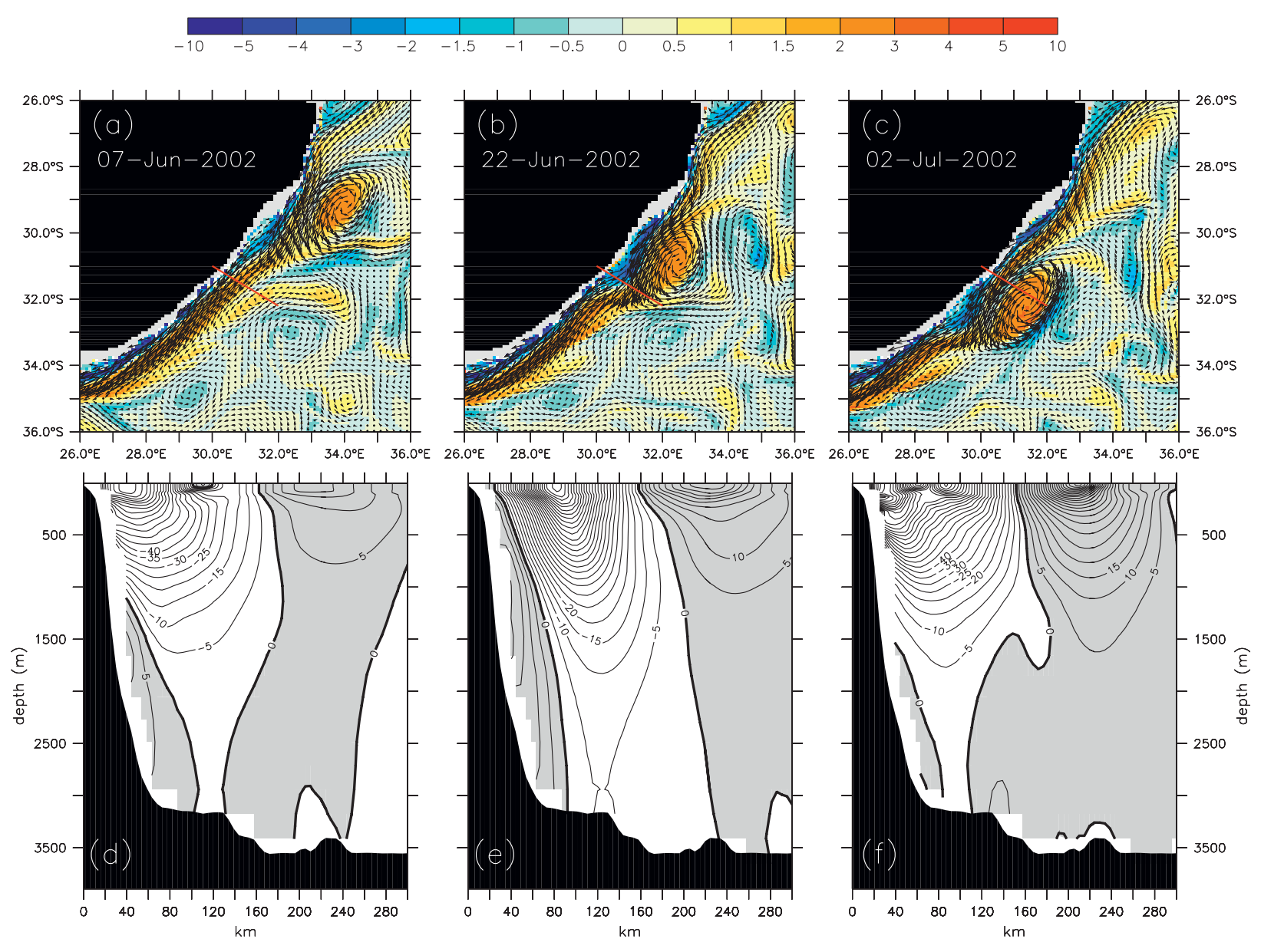

FIG. 6. Sample snapshots (5-day averages) (a),(d) before and during the transition of (b),(e) a Natal pulse and a consecutive (c),(f) Mozambique eddy: (a)-(c) vorticity (color, $10^{-5} \mathrm{~s}^{-1}$; blue, cyclonic; red, anticyclonic) and velocity (every second vector) at $100-\mathrm{m} \mathrm{depth}$, (d)-(f) simultaneous speeds in a section off Port Shepstone (similar to Fig. 2).

In summary, we have shown that the model performs well in simulating the structure, mean flow, and variability of the Agulhas Current and Undercurrent. We believe that this enables us to put the limited measurements of the Agulhas into a wider context using the dynamically consistent framework of the numerical model. In the rest of this paper we explore what drives the undercurrent and the effects of upstream perturbations on the Agulhas Current and Undercurrent structures and transports. Also, we examine a possible coherence of the Agulhas Undercurrent with other undercurrents to the north, by performing simulated float experiments.

\section{Interaction with upstream perturbations}

How does such interplay between upstream perturbations and the Agulhas Current system take place? From the available observations we have pieces of information about how Natal pulses perturb the Agulhas
Current system (Schouten et al. 2002), but no coherent picture. The seven observational snapshots of the velocity field at $32^{\circ} \mathrm{S}$ show that sometimes the Agulhas Current reaches down to the bottom, while at other times it covers only the upper $2000 \mathrm{~m}$ or so (Donohue et al. 2000; Beal 2009). Middepth floats and satellite data show cyclonically looping trajectories as meanders pass (Lutjeharms et al. 2001) and clear reversals of current direction at the sea surface (Lutjeharms and Connell 1989). In their Agulhas Current "movie," Bryden et al. (2005) describe the evolution of the velocity field during the passing of a Natal pulse. First, the Agulhas weakens and moves offshore, then the undercurrent strengthens and appears to penetrate upward until northward flow exists throughout the water column. At the same time, the Agulhas strengthens and there is strong cyclonic circulation across the section. Although highly significant to the Eulerian variance of the velocity field, interestingly Bryden et al. (2005) conclude that Natal 


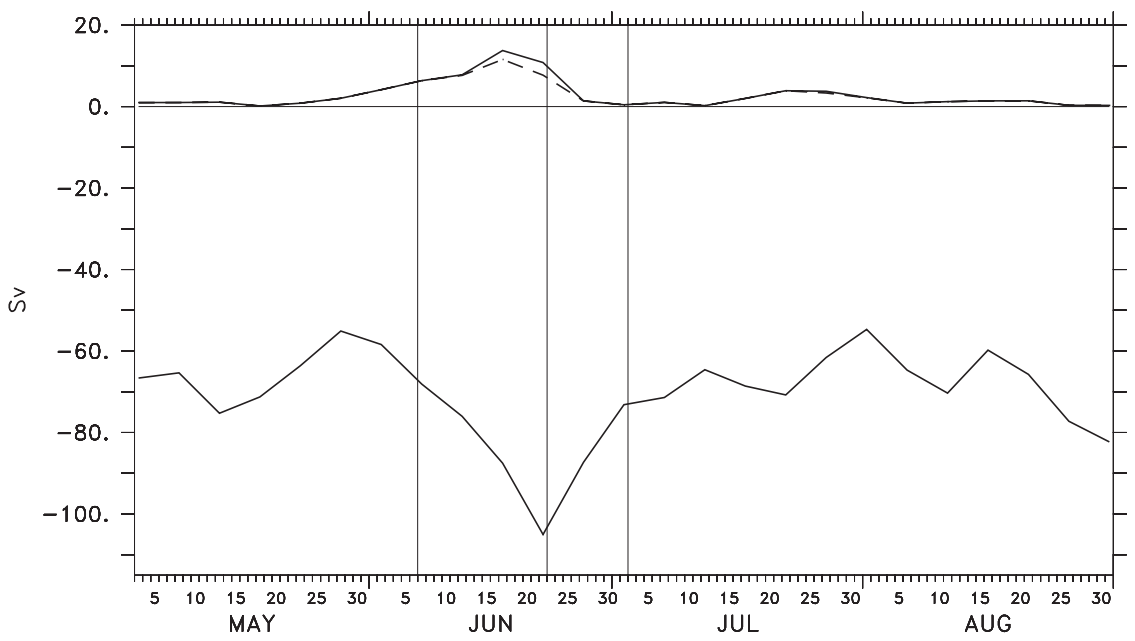

FIG. 7. Transports during the transition of a Natal pulse and a consecutive Mozambique eddy. Shown are the transport of the Agulhas Current (lower solid curve, integrated over the whole water column) and the undercurrent within the first $100 \mathrm{~km}$ (upper solid curve) and restricted to depths $>1000 \mathrm{~m}$ (dashed). The vertical lines display the centers of the 5-day averages shown in Fig. 6.

pulses do not cause a significant transport variance. In other words, from their data the meander mode appears to reflect a change in path but not in flux. However, Beal (2009) finds that the meander mode is dominant in the time series of Agulhas Undercurrent transport. How do these observations fit together? The Agulhas array does not resolve the undercurrent variability (and is limited to the upper $2400 \mathrm{~m}$ ) and the undercurrent array does not sample the Agulhas! A cohesive picture of top-tobottom variability from the model is therefore useful.

Figure 6 shows a representative series of snapshots from the model before and during the passing of a Natal pulse, attended by a Mozambique eddy. Plan views of the surface circulation, together with corresponding cross sections of the velocity field, are shown. In addition, Fig. 7 shows the evolution of transport in the current and undercurrent as the mesoscale perturbations propagate through. Prior to the arrival of the Natal pulse (Figs. 6a and $6 \mathrm{~d}$ ), the Agulhas Current is relatively stable with a transport of $\sim 70 \mathrm{~Sv}$ (Fig. 7) and a maximum speed of more than $1.05 \mathrm{~m} \mathrm{~s}^{-1}$ about $45 \mathrm{~km}$ offshore. Note that color shading depicts vorticity and the cyclonic region (in blue) is very narrow. The Natal pulse is triggered in the Natal Bight $\left(\sim 29^{\circ} \mathrm{S}\right)$ by a Mozambique eddy arriving from the north (Schouten et al. 2002). It causes a barotropic, northward velocity anomaly at the inshore side and a southward anomaly farther offshore (Figs. $6 \mathrm{~b}$ and $6 \mathrm{e})$. This then leads to an offshore displacement of the Agulhas Current by $40-50 \mathrm{~km}$ and a corresponding increase in speed over the whole water column (to 1.3 $\mathrm{m} \mathrm{s}^{-1}$ at the surface and still, and than $5 \mathrm{~cm} \mathrm{~s}^{-1}$ at the bottom) and transport (105 Sv). The cyclonic region of the current is now at its widest and strongest. Consequently, the lateral extent of the undercurrent increases, reaching up to the surface at the inshore side of the displaced Agulhas Current. Its core transport (limited to the inshore side of the Agulhas) peaks at $11.6 \mathrm{~Sv}$ (red line in Fig. 7). In this phase it is unclear how to distinguish an Agulhas Undercurrent from the countercurrent occurring at shallower depths (Lutjeharms and Connell 1989). Whether one defines the undercurrent here as all northward flow, or only northward flow below $1000 \mathrm{~m}$, the peaks in the Agulhas Undercurrent transport that are associated with passing Natal pulses are clearly evident in the temporal evolution (Fig. 7). The Mozambique eddy, directly following the Natal pulse, reverses anomalies (southward inshore and northward offshore), overshooting the Agulhas Current inshore (Figs. 6c and 6f) and decreasing its transport (Fig. 7). Due to the inshore position of the Agulhas Current, the undercurrent is now almost removed, and instead a strong northward countercurrent exists at the offshore side (Figs. 6c and 6f).

In summary, the model shows that the undercurrent transport peaks when the cyclonic vorticity is a maximum (Natal pulse), while the Agulhas Current transport peaks shortly after that (with the arriving Mozambique eddy). In addition, the undercurrent is completely stemmed on the flank of the passing Mozambique eddy (when the Agulhas is closest inshore), while the Agulhas Current's transport appears to be a minimum right at the end of the entire event after the eddy has passed through. The fact that the Agulhas Current transport's response is primarily to the offshore anticyclonic eddy, 


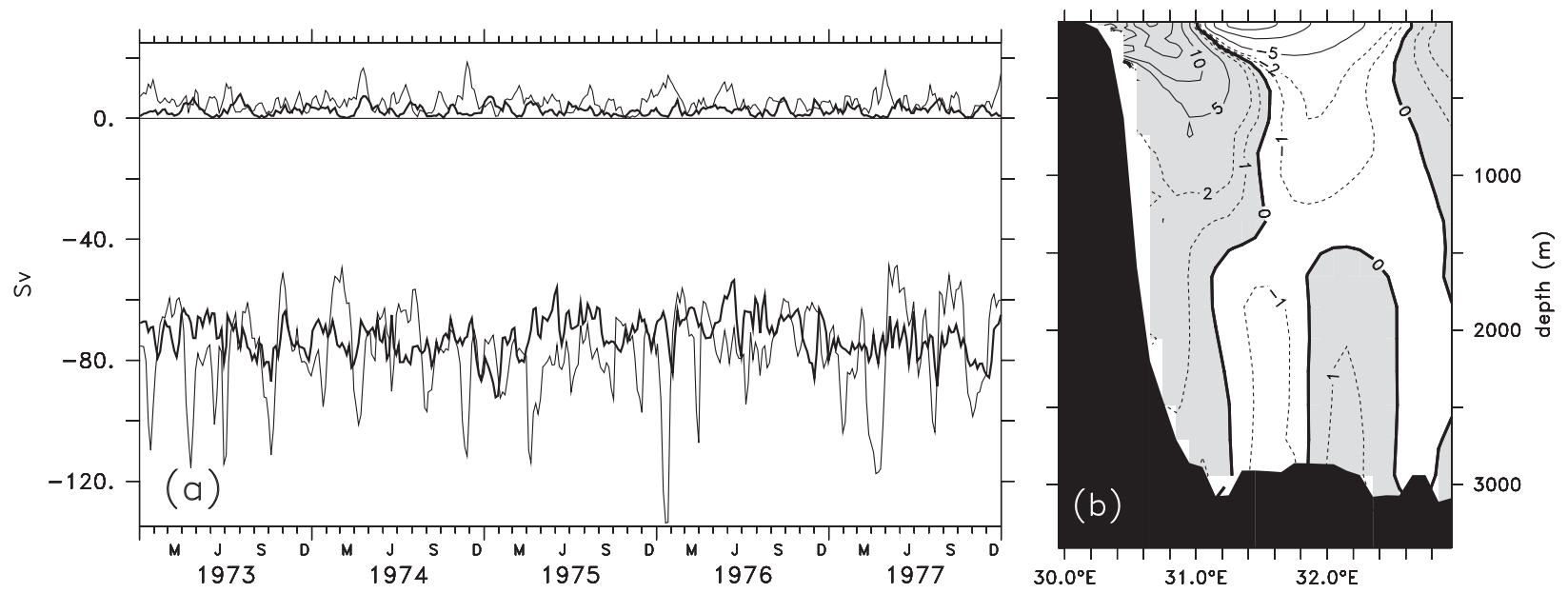

FIG. 8. (a) As in Fig. 5, but for the modeled Agulhas Current and Undercurrent in AG01-R (thin curves; with mesoscale perturbations from the north) and AG01-S (thick curves; without impinging perturbations). (b) Time-mean differences at $31^{\circ} \mathrm{S}$ between AG01-R and AG01-S. [Positive values (i.e., a larger Agulhas Current and Undercurrent in AG01-R) are shaded gray. The solid lines have a contour interval of $5 \mathrm{~cm} \mathrm{~s}^{-1}$; dashed lines indicate values between -2 and $2 \mathrm{~cm} \mathrm{~s}^{-1}$.]

rather than to the Natal pulse, may explain why Bryden et al. (2005) saw only relatively moderate transport responses in their movie frames showing a Natal pulse.

To test further whether these solitary meander events, involving the interplay of Natal pulses and Mozambique eddies, really represent a transport mode for the Agulhas, we have run a model experiment excluding Mozambique eddies. Experiment AG01-S reduces the high-resolution nest to the region south of the Mozambique Channel, thus effectively preventing Mozambique eddies and $\mathrm{Na}$ - tal pulses from being formed. Figure 8 shows that variations in both Agulhas and undercurrent transport are significantly reduced in the absence of upstream perturbations; extreme values are less prevalent and the standard deviation is just half of the reference case (Table 1). Interestingly, the mean currents are also reduced, especially, the Agulhas Undercurrent, which undergoes a $50 \%$ reduction in volume transport when upstream perturbations are no longer part of the model simulation. The difference in the mean velocity fields from our

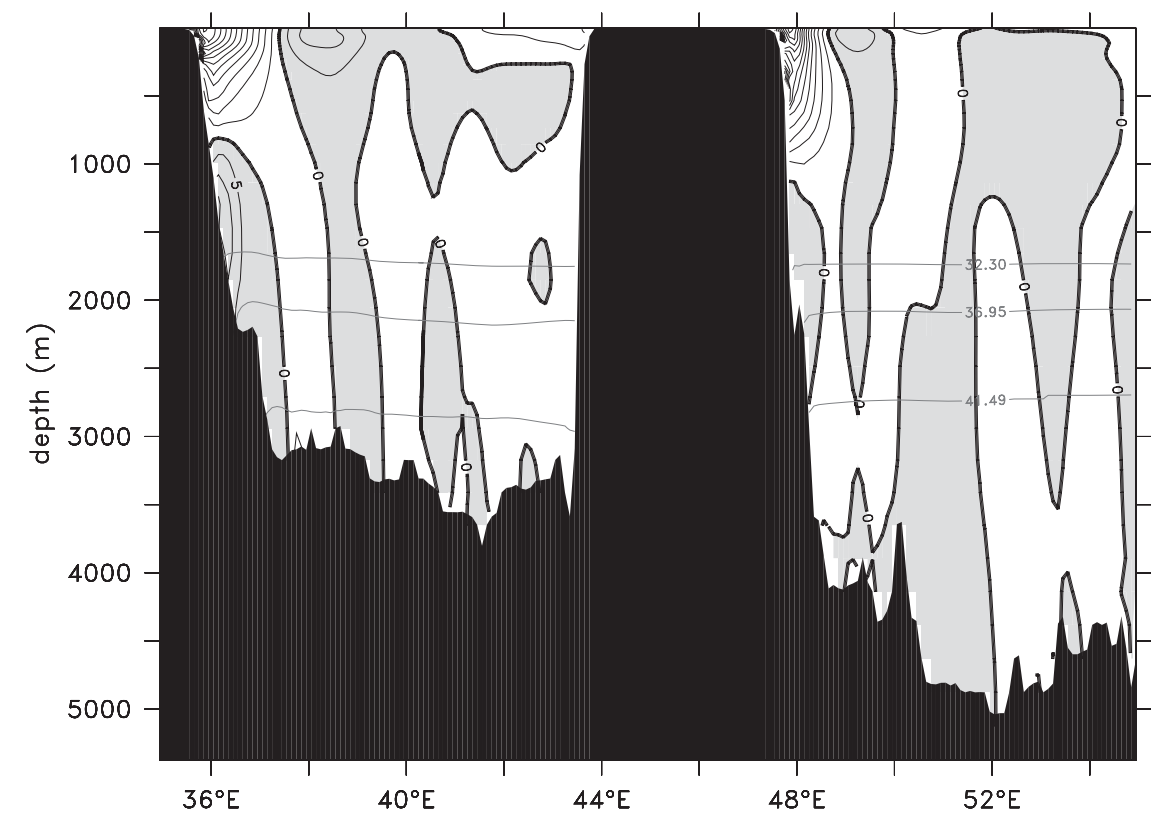

FIG. 9. As in Fig. 2, but at $24^{\circ} \mathrm{S}$ covering the Mozambique Channel and the Southeast Madagascar Current region. Undercurrents with different strengths are evident at each location. 


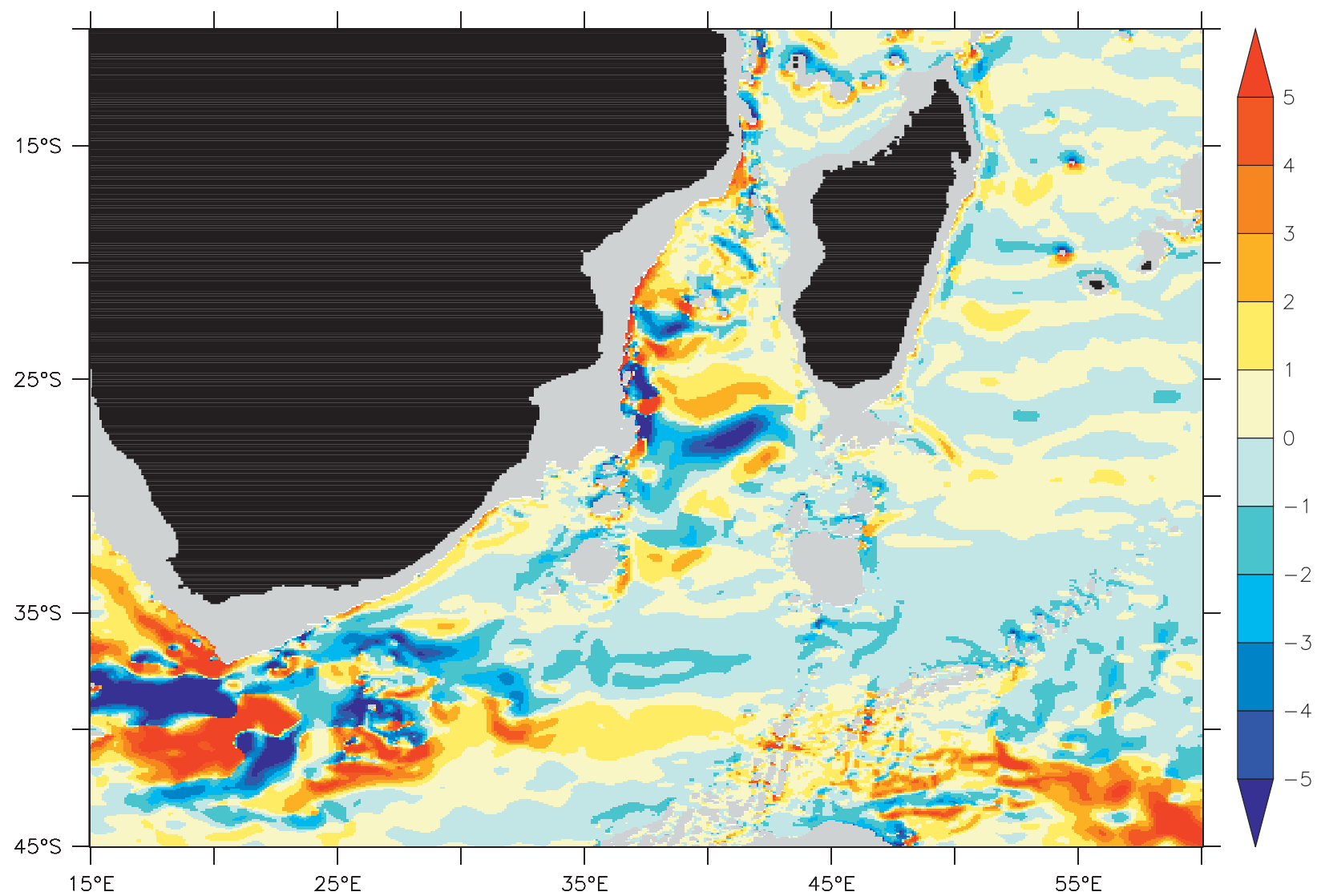

FIG. 10. Deep flow in the southwest Indian Ocean. Model speeds (1995-2004 mean, $\mathrm{cm} \mathrm{s}^{-1}$ ) have been averaged between $2000-$ and 3000-m depths. To indicate the direction of the flow northward (southward), velocities are positive (negative) and displayed in warm (cold) colors.

original model run and the run without Mozambique eddies is shown in Fig. 8 b. Figure $8 b$ indicates that the influence of the upstream perturbations is rectified at $32^{\circ} \mathrm{S}$ as a surface-intensified cyclonic circulation, which acts to strengthen the undercurrent and weaken the Agulhas onshore, while strengthening the Agulhas offshore. Due to the barotropic nature of the Mozambique eddies, their net transport reaches down to the bottom.

These model results imply that the undercurrent is (partially) driven by the mesoscale perturbations arriving from the north and is not necessarily a continuum from south to north. This question will be examined in the next sections.

\section{Pathways of the Agulhas Undercurrent}

As mentioned above, undercurrents have not only been observed under the Agulhas Current but also in the Mozambique Channel (de Ruijter et al. 2002) and east of Madagascar (Nauw et al. 2008). Water mass analysis (the presence of NADW) suggests that the Agulhas Undercurrent and the undercurrent in the Mozambique
Channel may in some way be connected (van Aken et al. 2004). Both these undercurrents in the source regions of the Agulhas Current exist in the model as well (Fig. 9), and with similar strengths compared to the observed transports. In this part of our analysis we ask: What is the latitudinal extent of the Agulhas Undercurrent and does it connect with and supply the Mozambique and East Madagascar Undercurrents with deep water of Atlantic origin? An inspection of the time-mean flow between 2000 and $3000 \mathrm{~m}$ in the model (Fig. 10) does not support any kind of direct connection.

The simulated Agulhas Undercurrent is clearly present as a narrow stream of northward flow between $36^{\circ}$ and $30^{\circ} \mathrm{S}$ along the South African continental slope (Fig. 10). The latitude $35^{\circ} \mathrm{S}$ (southwest of Port Elizabeth) corresponds to the latitude at which observations show the Agulhas Current separates from the slope and flows into deeper water. At $30^{\circ} \mathrm{S}$, the continental slope shoals and widens and the simulated undercurrent is pushed offshore and seems to diffuse. This model portrayal is corroborated by observations that hint at an offshore core of northward flow off Richards Bay at $30^{\circ} \mathrm{S}$ (Casal 


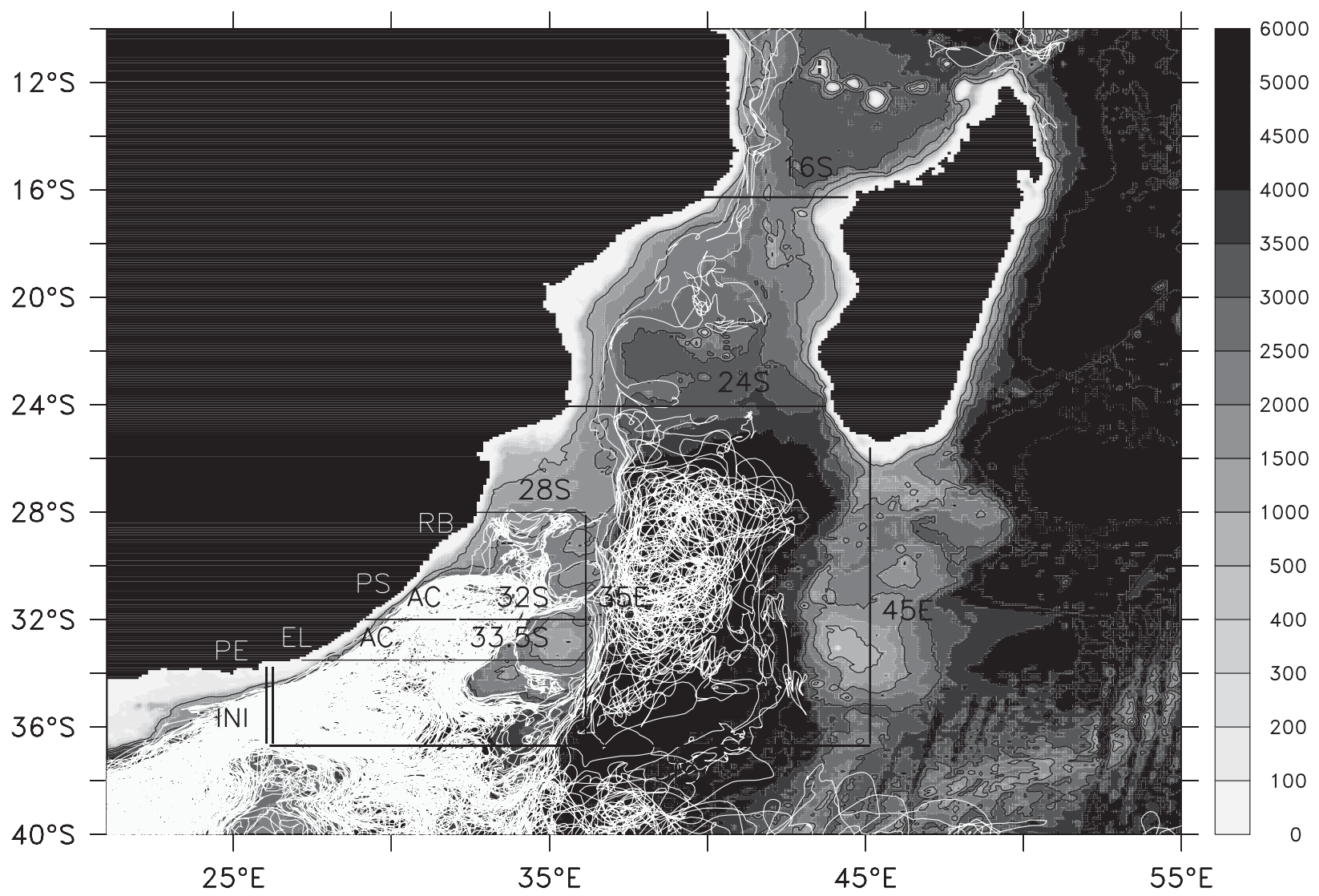

FIG. 11. A subset of trajectories for floats that were released continuously during 1980 in the Agulhas Undercurrent $\left(\sigma_{1} \geq 32.30\right)$ at $26^{\circ} \mathrm{E}$ (double line) and integrated until 2000. Shaded in gray is the bathymetry in $\mathrm{m}$; contour lines are drawn with an interval of $1000 \mathrm{~m}$. Section names correspond to Table 2. (Note that the quantification shown in Table 2 uses many more floats and spans a longer time interval.) Marked are locations of Richards Bay (RB), Port Shepstone (PS), East London (EL), and Port Elizabeth (PE).

2008). Once the undercurrent has diffused in the northern Natal Valley, there is no more evidence in the model for a coherent boundary flow to the north until $25^{\circ} \mathrm{S}$ to the east of Madagascar and $23^{\circ} \mathrm{S}$ in the Mozambique Channel. However, there is some evidence for deep flow out of the Natal Valley and into the Mozambique Basin, through the gaps in the Mozambique Ridge.

To examine pathways in the model, a Lagrangian analysis is better suited than a simple Eulerian field since it will reveal all possible pathways and allow one to quantify fluxes between one location and another. In our first Lagrangian experiment about 500000 virtual floats were released at $26^{\circ} \mathrm{E}$ (double line in Fig. 11), in flow with an eastward component and with densities $\sigma_{1} \geq 32.30$, thus representing only the flux of NADW into the Indian Ocean. Examples of float trajectories are shown in Fig. 11; the full statistics (Table 2) have been calculated over $20 \mathrm{yr}$ of integration. About $7 \mathrm{~Sv}$ of NADW enters the northern Agulhas Basin between the African continent and the Agulhas Plateau, but almost $70 \%$ directly leaves westward across the same section.
About $10 \%$ (less than $1 \mathrm{~Sv}$ ) of the remaining volume flux of NADW finds its way across up to $32^{\circ} \mathrm{S}$, mainly directly under the southward-flowing Agulhas Current (i.e., within the undercurrent). North of $\sim 29^{\circ} \mathrm{S}$, northward movement is entirely blocked by shallower topography, and only a few floats ( $4 \%$, representing $0.3 \mathrm{~Sv}$ ) find their way through narrow topographic gaps in the Mozambique Ridge $\left(36.5^{\circ} \mathrm{E}\right)$ and into the Natal Basin. Very few floats (representing less than $0.1 \mathrm{~Sv}$ ) enter the southern entrance of the Mozambique Channel within this 20 -yr period.

To examine the meridional coherence of the Agulhas Undercurrent along the African coast further, an additional experiment was performed where floats were released at $33.5^{\circ} \mathrm{S}$ (Fig. 12, Table 3). Here, 37\% (1 Sv) form a continuous flow under the Agulhas Current up to $32^{\circ} \mathrm{S}$ and farther. But, $60 \%$ eventually leave southward across $33.5^{\circ} \mathrm{S}$, carried by the Agulhas Current or its associated upstream perturbations. Again, a very small number of floats do ultimately escape the Natal Valley through or around the Mozambique Ridge $\left(34^{\circ} \mathrm{E}\right)$ and into the 
TABLE 2. Quantitative float calculations released at $26^{\circ} \mathrm{E}(1980$ $84)$ in the eastward-flowing AUC marked by the density range $\sigma_{1} \geq 32.30$ and integrated for another $20 \mathrm{yr}$ (1985-2004). Sections correspond to Fig. 11. (The top section of the table spans the large control volume indicated by the boldface lines in Fig. 11; additional control sections are marked by thin lines.) Numbers are in Sv and $\%$ relative to the total transport through the seeding section.

\begin{tabular}{lrr}
\hline \hline & \multicolumn{2}{c}{ AUC } \\
\cline { 2 - 3 } & $(\mathrm{Sv})$ & $(\%)$ \\
\hline $26^{\circ} \mathrm{E}(\mathrm{INI})$ & 4.76 & 69 \\
$36^{\circ} \mathrm{S}$ & 2.06 & 30 \\
$45^{\circ} \mathrm{E}$ & 0.00 & 0 \\
$16^{\circ} \mathrm{S}$ & 0.01 & 0 \\
Interior & 0.10 & 1 \\
& & \\
Total & 6.93 & 100 \\
& & \\
Additional control sections & & 9 \\
$33.5^{\circ} \mathrm{S}(\mathrm{AC})$ & 0.64 & 9 \\
$33.5^{\circ} \mathrm{S}$ & 0.04 & 0 \\
$32.0^{\circ} \mathrm{S}(\mathrm{AC})$ & 0.60 & 0 \\
$32.0^{\circ} \mathrm{S}$ & 0.02 & 2 \\
$28.0^{\circ} \mathrm{S}$ & 0.01 & 2 \\
$36.6^{\circ} \mathrm{E}$ & 0.15 & 1 \\
$36.6^{\circ} \mathrm{E}\left(>33.5^{\circ} \mathrm{S}\right)$ & 0.15 & \\
$24^{\circ} \mathrm{S}$ & 0.07 & \\
\hline
\end{tabular}

Mozambique Basin; however, none makes it across to the East Madagascar Undercurrent over this entire period. Over the 20-yr integration, most of the deep floats remain trapped within the Natal Valley region.

So where does the deep flow in the Mozambique and East Madagascar Undercurrents come from? A third experiment (Fig. 13) has been performed in which floats were released at $24^{\circ} \mathrm{S}$ and densities $\sigma_{1} \geq 32.30$ in the Mozambique Channel and integrated backward in time to establish the origin of this water. In this case more than $60 \%$ of the floats (11 Sv in total, sections INI and north in Table 4) crossed the section from the north, about equal numbers crossed to the west and east. Hence, they are part of a (re)circulation in the Mozambique Channel or arrive via Mozambique eddies. This situation is quite similar to the recirculating nature of the Agulhas Current system. About $28 \%$ enter the channel from the east $\left(45^{\circ} \mathrm{E}\right.$, sections EMC and east in Table 4$)$. Only $5 \%$ enter from the south (south in Table 4) and virtually no floats $(1 \%$ or $0.08 \mathrm{~Sv}, \mathrm{AC})$ were previously in the Agulhas Undercurrent at $32^{\circ} \mathrm{S}$. A similar experiment (not shown) was performed for the undercurrent beneath the Southeast Madagascar Current, also showing no significant connection to the Agulhas Undercurrent.

The three float experiments all draw a similar picture: the continuous flow of the Agulhas Undercurrent along the African shelf is small ( $1 \mathrm{~Sv})$. Most of the flow is detrained into the Agulhas Current or eddies or is eventually blocked by topography; just a minor portion is able to enter the Mozambique Basin. A connection between deep floats in the Agulhas Undercurrent and those in the Mozambique Channel is tenuous, tested both forward and backward in time.

Naturally, the model is not reality and it may not represent the undercurrents and the deep flows in the southwestern Indian Ocean well. Water mass structures, especially in combination with topographic slopes, are not a typical strength of $z$-coordinate models (Legg et al. 2006). Deficits could also arise if the source regions of the undercurrents are outside the high-resolution nest, which are not properly represented at coarse resolution. The model described here does show a good reproduction of the Agulhas Current and Undercurrent at $32^{\circ} \mathrm{S}$, as well as their dominant forms of variability. The simulated Agulhas Undercurrent is too weak compared to Beal's (2009) measurements, and this could mean that throughflow transports and connections into the Mozambique Channel are underrepresented in the model. But observations, in particular the lack of a water mass signature in the undercurrent, support the general results of the model analysis: that detrainment from the undercurrent is very high, that the deep water circulation is dominated by eddying and recirculations, and that the residence time in the Natal Valley is large.

\section{Discussion and conclusions}

The goals of this study were to expand on the available observations of the Agulhas Current system in order to better understand its variability and to examine the pathways into and out of the Agulhas Undercurrent. For our analysis we have used the dynamically consistent framework of a high-resolution ocean general circulation model to explore the effect of perturbations, in particular Mozambique eddies and Natal pulses, on the velocity field and transports of the Agulhas Current and Undercurrent and to conduct virtual float experiments that highlight the pathways and fluxes of deep flows.

Comparison of the model with snapshot observations at a number of latitudes, and in particular with a composite mean velocity field at the historic $32^{\circ} \mathrm{S}$ section, shows a generally good performance of the model with respect to the western boundary current structure. The modeled Agulhas Current exhibits the characteristic v-shape structure and depth dependency with an undercurrent below and inshore of it. Although slightly weaker in its mean velocities, it has a volume transport that is similar to the observations. As for transports, the model simulates the peak-to-peak variability and 50-70-day periodicity observed in the Agulhas Current well (Bryden et al. 2005). Deep northward transports are also similar between the 


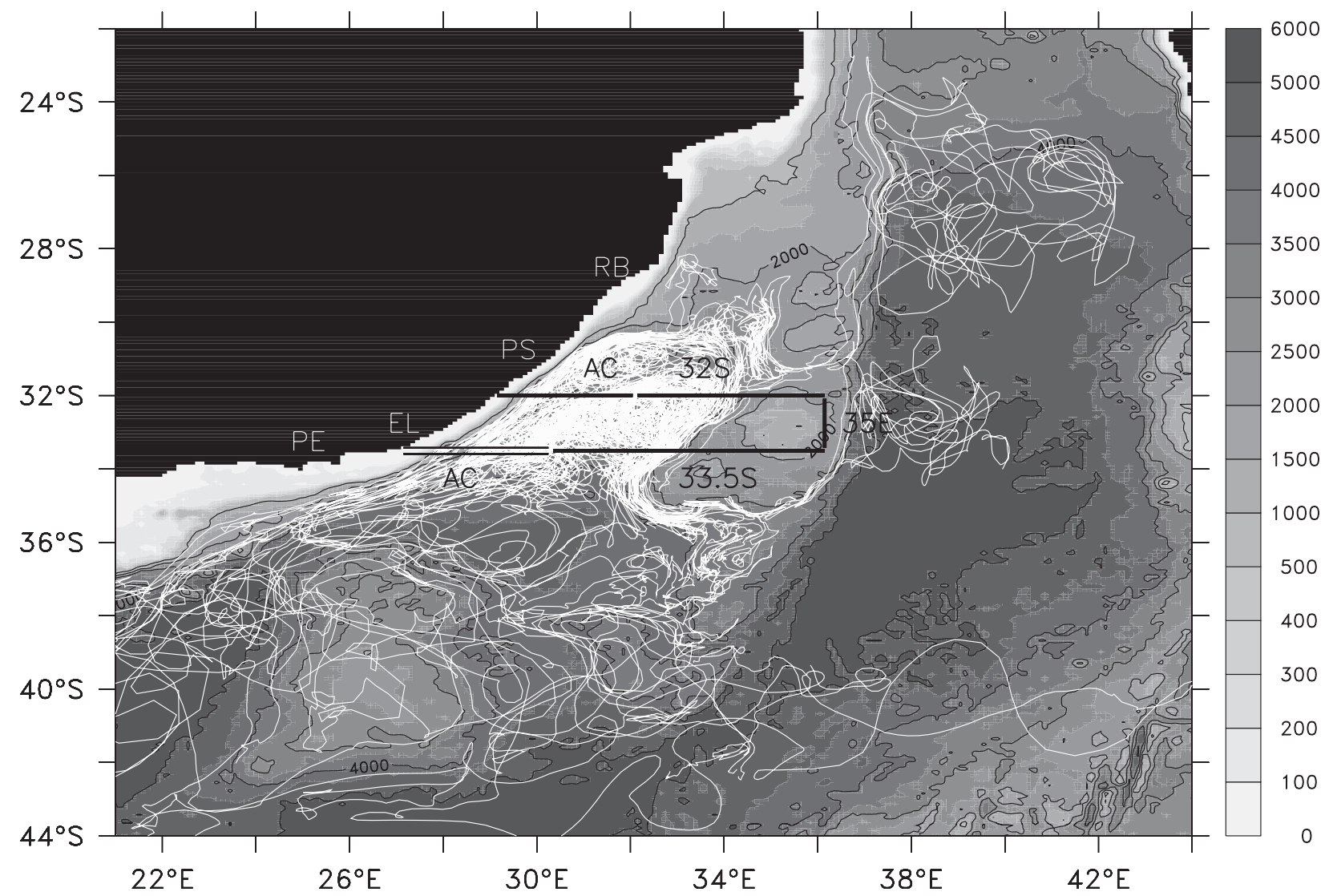

FIG. 12. As in Fig. 11, but with ample floats released continuously during 1995 in the Agulhas Undercurrent $\left(\sigma_{1} \geq 32.30\right)$ at $32^{\circ} \mathrm{S}($ double line) and with the trajectories integrated until 2004. Section names correspond to Table 3.

model and observations, and the transport of the undercurrent is comparable to Bryden et al. (2005) but somewhat weaker in the model $(2.7 \pm 2.6 \mathrm{~Sv})$ compared to the more recent values of Beal (2009) $(4.2 \pm 5.2 \mathrm{~Sv})$.

It is clear that horizontal grid resolution is a necessary requirement to properly represent the Agulhas Undercurrent in a numerical model. The $1 / 2^{\circ}$ global model alone [Biastoch et al. (2008a), not including a high-resolution Agulhas nest] does not show any northward flow beneath the Agulhas Current; at $1 / 4^{\circ}$ resolution (DRAKKAR Group 2007) small velocities are visible, yet are too small, resulting in a mean transport that is only a quarter of the value obtained in this study. However, resolution alone is not a sufficient criterion. Despite its high resolution, the Parallel Ocean Program (POP) model underestimates the transport at 1.1 Sv (Maltrud and McClean 2005), probably due to the full bottom cell representation in this $z$-coordinate model, typically resulting in a poor representation of topographic slopes. In contrast, the Norwegian Ecological Model System (NORWECOM), with about $1 / 5^{\circ}$ resolution but a terrain-following depth representation, shows a reasonable representation (Skogen 1999). The model for which results are shown here over- comes the typical deficits of a $z$-coordinate model by allowing partially filled bottom cells. This generally leads to an improved representation of the topographic slopes.

Analysis of meander events in the model shows that they consist of paired Natal pulses (cyclonic) and Mozambique eddies (anticyclonic). These are the dominant cause of Eulerian transport variability in both the Agulhas Current and the Agulhas Undercurrent. Peak undercurrent transports are associated with the passing of

TABLE 3. As in Table 2, but with floats released at $33.5^{\circ} \mathrm{S}(1980$ 84) and integrated for another 5 yr (1985-1990). Section names correspond to those used in Fig. 12.

\begin{tabular}{lrr}
\hline \hline & \multicolumn{2}{c}{ AUC } \\
\cline { 2 - 3 } & $(\mathrm{Sv})$ & $(\%)$ \\
\hline $33.5^{\circ} \mathrm{S}(\mathrm{INI})$ & 1.46 & 54 \\
$33.5^{\circ} \mathrm{S}$ & 0.17 & 6 \\
$36^{\circ} \mathrm{E}$ & 0.00 & 0 \\
$32^{\circ} \mathrm{S} \mathrm{AC}$ & 1.00 & 27 \\
$32^{\circ} \mathrm{S}$ & 0.06 & 0 \\
Interior & 0.00 & 100 \\
& & \\
Total & 2.68 & \\
\hline
\end{tabular}




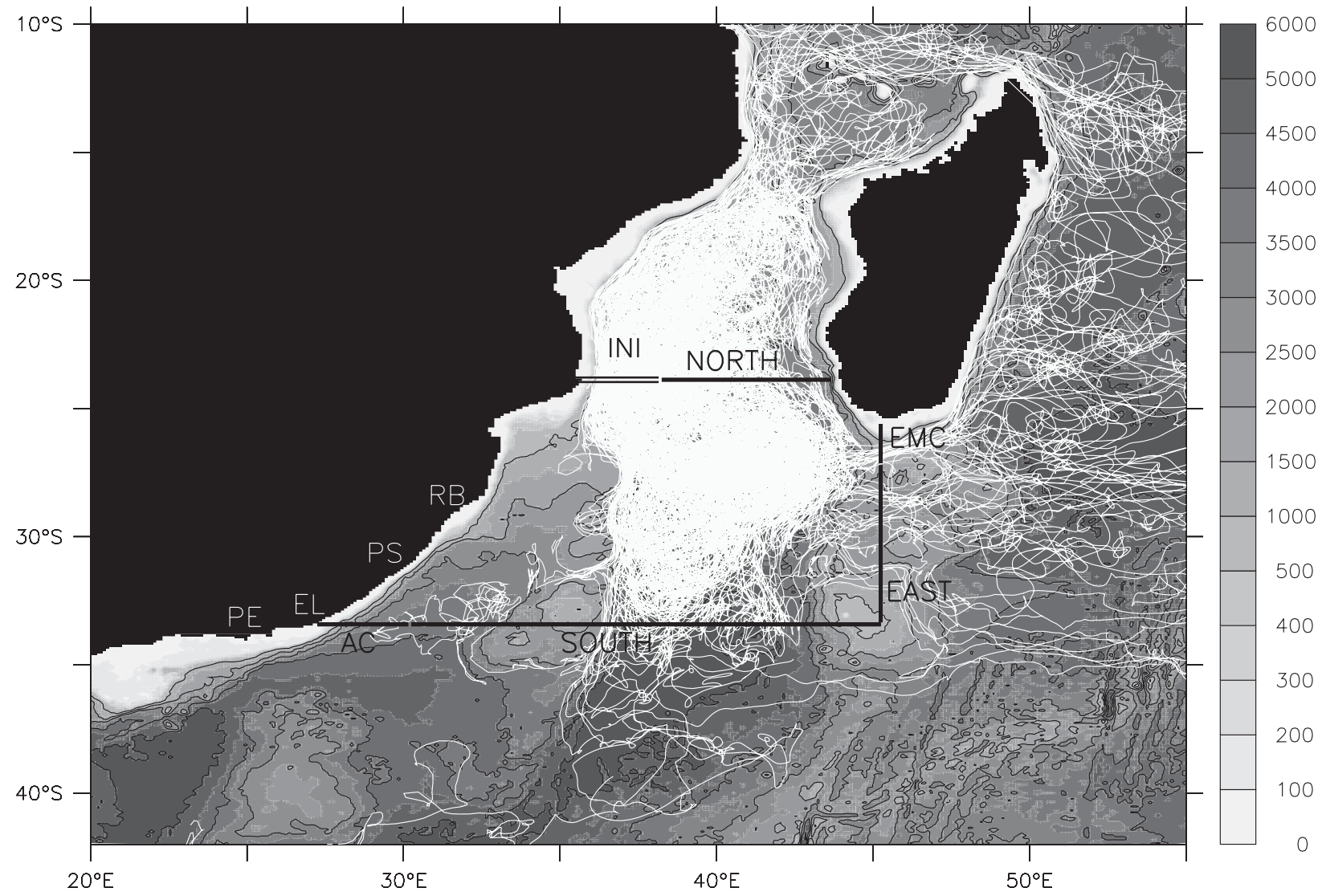

FIG. 13. As in Fig. 11, with but ample floats released continuously during 2004 in the Mozambique Channel at $24^{\circ} \mathrm{E}$ (double line) and backward integrated for another $19 \mathrm{yr}$ (1985-2003). Section names correspond to Table 4.

a Natal pulse, while peak Agulhas Current transports are associated with the juxtaposition of a Mozambique eddy. As the eddy passes and the Agulhas Current moves onshore, the undercurrent is entirely "squeezed" out and its waters must be detrained into the Agulhas Current. Most importantly, in a model run with no meanders, the mean and standard deviation of undercurrent transport are halved. In other words, rectification of the Natal pulses seems to account for a large proportion of the undercurrent flow. This is consistent with a similar study by Nakamura et al. (2008) who examined the deep countercurrent beneath the Kuroshio in both mooring records and a global high-resolution model (Matsumoto et al. 2004). They found eddy motions due to Kuroshio meanders being organized into a persistent countercurrent at depth, a mechanism that they interpreted as resulting from the Neptune effect (Holloway 1992). In the Agulhas Current case, direct velocity observations have shown an undercurrent on every occupation, not just on occupations where a Natal pulse is present, and the undercurrent mooring array showed that only during $10 \%$ of the time is northward flow completely absent. Moreover, there is good argument that thermohaline forcing encourages
NADW flow beneath the Agulhas. Hence, rectification is not the complete story, but it seems likely that a significant proportion of the undercurrent is owed to solitary meanders of the Agulhas Current. We note that defining the Agulhas Undercurrent as only northward flow allows for the change in variability of the flow to have a large effect on the mean.

TABLE 4. As in Table 2, but with floats released at $24^{\circ} \mathrm{S}(2000$ 2004) in northward flows below $680 \mathrm{~m}$ (model level 22) and integrated backward over another 20 yr (1999-1980). Section names correspond to Fig. 13. The "INI surface" is the water column shallower than $680 \mathrm{~m}$.

\begin{tabular}{lrr}
\hline \hline & \multicolumn{2}{c}{ MOZ backward } \\
\cline { 2 - 3 } & $(\mathrm{Sv})$ & $(\%)$ \\
\hline INI & 2.92 & 2 \\
North & 3.90 & 35 \\
EMC & 0.64 & 6 \\
East & 2.39 & 22 \\
South & 0.58 & 5 \\
AC & 0.08 & 1 \\
INI Surface & 0.36 & 3 \\
Interior & 0.14 & 1 \\
Total & 11.01 & 100 \\
\hline
\end{tabular}


The model mean field shows that the latitudinal extent of the undercurrent is constrained between $36^{\circ}$ and $30^{\circ} \mathrm{S}$, in other words, to the region where the Agulhas Current lies close to the continental slope. Hence, the organization of the deep flow into a narrow boundary flow appears to be dependent on the existence of the Agulhas Current and/or its perturbations. The pathways of deep water within the Agulhas Current system are highlighted by our float experiments and show that there is only a tenuous connection between the Agulhas Undercurrent and undercurrents to the north, in the Mozambique Channel and under the East Madagascar Current. Moreover, the Lagrangian net transports are very much smaller than the Eulerian transports, because detrainment and eddying motions dominate the flow field. As a net value, less than $1 \mathrm{~Sv}$ of deep water flows through the gap between the African continent and the Agulhas Plateau, to continue northward within the undercurrent.

Ultimately, the model suggests that the Agulhas Undercurrent has little effect on the ventilation of the Indian Ocean, beyond the Natal Valley. Since observations show traces of upper NADW within the Mozambique Channel, the model likely underestimates the fluxes. However, it is clear that no direct path for NADW exists, but rather that there is a convoluted path dominated by eddying motions, which result in long residence times.

Acknowledgments. The integration of the experiments has been performed at the Höchstleistungsrechenzentrum Stuttgart (HLRS) and the Computing Centre at Kiel University. We gratefully thank the NEMO and AGRIF system teams as well as Jean-Marc Molines and Markus Scheinert for their technical support. The analysis was performed under DFG Project BO 907/2-2 and the BMBF German-South African bilateral agreement (SUA 07/004). JL received support from the Alexander von Humboldt Foundation and expresses his appreciation to the Stellenbosch Institute for Advanced Studies (STIAS) for a special fellowship to complete his contribution.

\section{REFERENCES}

Alvarez-Garcia, F., M. Latif, and A. Biastoch, 2008: On multidecadal and quasi-decadal North Atlantic variability. J. Climate, 21, 3433-3452.

Arakawa, A., and Y.-J. G. Hsu, 1990: Energy conserving and potential-enstrophy dissipating schemes for the shallow water equations. Mon. Wea. Rev., 118, 1960-1969.

Arhan, M., H. Mercier, and Y. Park, 2003: On the deep water circulation of the eastern South Atlantic Ocean. Deep-Sea Res. I, 50, 889-916.

Barnier, B., and Coauthors, 2006: Impact of partial steps and momentum advection schemes in a global ocean circulation model at eddy permitting resolution. Ocean Dyn., 56, doi:10.1007/s10236-006-0082-1.

Beal, L., 2009: A time series of Agulhas Undercurrent transport. J. Phys. Oceanogr., 39, 2436-2450.

— dercurrent. Deep-Sea Res., 44, 1715-1724.

— , and H. Bryden, 1999: The velocity and vorticity structure of the Agulhas Current at 32S. J. Geophys. Res., 104, 5151-5176.

—, T. Chereskin, Y. Lenn, and S. Elipot, 2006: The sources and mixing characteristics of the Agulhas Current. J. Phys. Oceanogr., 36, 2060-2074.

Béranger, K., B. Barnier, S. Gulev, and M. Crépon, 2006: Comparing 20 years of precipitation estimates from different sources over the World Ocean. Ocean Dyn., 56, 104-138.

Biastoch, A., C. Böning, J. Getzlaff, J.-M. Molines, and G. Madec, 2008a: Causes of interannual-decadal variability in the meridional overturning circulation of the midlatitude North Atlantic Ocean. J. Climate, 21, 6599-6615.

,$- \ldots$, and J. Lutjeharms, 2008b: Agulhas leakage dynamics affects decadal variability in Atlantic overturning circulation. Nature, 456, 489-492, doi:10.1038/nature07426.

,,,--- and M. Scheinert, 2008c: Mesoscale perturbations control inter-ocean exchange south of Africa. Geophys. Res. Lett., 35, L20602, doi:10.1029/2008GL035132.

Blanke, B., and P. Delecluse, 1993: Variability of the tropical Atlantic Ocean simulated by a general circulation model with two different mixed-layer physics. J. Phys. Oceanogr., 23, 1363-1388.

_- M. Arhan, G. Madec, and S. Roche, 1999: Warm water paths in the equatorial Atlantic as diagnosed with a general circulation model. J. Phys. Oceanogr., 29, 2753-2768.

Bryden, H., and L. Beal, 2001: Role of the Agulhas Current in Indian Ocean circulation and associated heat and freshwater fluxes. Deep-Sea Res. I, 48, 1821-1845.

,-- , and L. Duncan, 2005: Structure and transport of the Agulhas Current and its temporal variability. J. Oceanogr., 61, 479-492.

Casal, T., 2008: The structure of the Agulhas Current system during the Agulhas Undercurrent Experiment. Ph.D. thesis, Rosenstiel School of Marine and Atmospheric Science, University of Miami, Miami, FL, 163 pp.

_ L. M. Beal, R. Lumpkin, and W. E. Johns, 2009: Structure and downstream evolution of the Agulhas Current system during a quasi-synoptic survey in February-March 2003. J. Geophys. Res., 114, C03001, doi:10.1029/2008JC004954.

Chelton, D. B., R. A. DeSzoeke, M. G. Schlax, K. E. Naggar, and N. Siwertz, 1998: Geographical variability of the first baroclinic rossby radius of deformation. J. Phys. Oceanogr., 28, 433-460.

Conkright, M., and Coauthors, 2002: Introduction. Vol. 1, World Ocean Database 2001, NOAA Atlas NESDIS 42, 167 pp.

Debreu, L., C. Vouland, and E. Blayo, 2008: AGRIF: Adaptive grid refinement in Fortran. Comput. Geosci., 34, 8-13.

de Ruijter, W. P. M., A. Biastoch, S. S. Drijfhout, J. R. E. Lutjeharms, R. Matano, T. Pichevin, P. J. van Leeuwen, and W. Weijer, 1999a: Indian-Atlantic inter-ocean exchange: Dynamics, estimation and impact. J. Geophys. Res., 104, 20 885-20 910.

— , P. J. van Leeuwen, and J. R. E. Lutjeharms, 1999b: Generation and evolution of Natal pulses: Solitary meanders in the Agulhas Current. J. Phys. Oceanogr., 29, 3043-3055.

- H. Ridderinkhof, J. Lutjeharms, M. Schouten, and C. Veth, 2002: Observations of the flow in the Mozambique Channel. Geophys. Res. Lett., 29, L1502, doi:10.1029/2001GL013714. 
Donohue, K., E. Firing, and L. Beal, 2000: Comparison of three velocity sections of the Agulhas Current and Agulhas Undercurrent. J. Geophys. Res., 105, 28 585-28 593.

DRAKKAR Group, 2007: Eddy-permitting ocean circulation hindcasts of past decades. CLIVAR Exchanges, No. 42 (Vol. 12, No. 3), International CLIVAR Project Office, Southampton, United Kingdom, 8-10.

Fox, A. D., and S. J. Maskell, 1996: A nested primitive equation model of the Iceland-Faeroe front. J. Geophys. Res., 101, 18 259-18 278.

Griffies, S. M., and Coauthors, 2009: Coordinated ocean-ice reference experiments (COREs). Ocean Modell., 26, doi:10.1016/ j.ocemod.2008.08.007.

Gründlingh, M. L., 1980: On the volume transport of the Agulhas Current. Deep-Sea Res., 27, 557-563.

Holloway, G., 1992: Representing topographic stress for largescale ocean models. J. Phys. Oceanogr., 22, 1033-1046.

Jacobs, S., and D. Georgi, 1977: Observations on the southwest Indian/Antarctic Ocean. Deep-Sea Res., 24, 43-84.

Kalnay, E., and Coauthors, 1996: The NCEP/NCAR 40-Year Reanalysis Project. Bull. Amer. Meteor. Soc., 77, 437-471.

Large, W. G., and S. G. Yeager, 2004: Diurnal to decadal global forcing for ocean and sea-ice models: The data sets and flux climatologies. NCAR Tech. Note NCAR/TN-460+STR, $111 \mathrm{pp}$.

Latif, M., C. Böning, J. Willebrand, A. Biastoch, J. Dengg, N. Keenlyside, G. Madec, and U. Schweckendiek, 2006: Is the thermohaline circulation changing? J. Climate, 19, 4631-4637.

Legg, S., R. Hallberg, and J. Girton, 2006: Comparison of entrainment in overflows simulated by $\mathrm{z}$-coordinate, isopycnal and non-hydrostatic models. Ocean Modell., 11, 69-97.

Lübbecke, J., C. Böning, and A. Biastoch, 2008: Variability in the subtropical-tropical cells and its effect on near-surface temperature of the equatorial Pacific: A model study. Ocean Sci., 4, 73-88.

Lutjeharms, J., 1972: A quantitative assessment of year-to-year variability in water movement in the south-west Indian Ocean. Nature, 239, 59-60.

— 2006: The Agulhas Current. Springer, 329 pp.

Lutjeharms, J. R. E., and H. R. Roberts, 1988: The Natal pulse: An extreme transient on the Agulhas Current. J. Geophys. Res., 93, 631-645.

_ , and R. van Ballegooyen, 1988: Anomalous upstream retroflection in the Agulhas Current. Science, 240, 1770-1770.

—_, and A. Connell, 1989: The Natal pulse and inshore counter currents off the South African east coast. S. Afr. J. Sci., 85, 533-535.

—, O. Boebel, P. C. F. van der Vaart, W. P. M. de Ruijter, T. H. Rossby, and H. L. Bryden, 2001: Evidence that the Natal pulse controls the Agulhas Current to its full depth. Geophys. Res. Lett., 28, 3449-3452.

Madec, G., 2006: NEMO ocean engine. Note du Pole de Modelisation 27, Institut Pierre Simon Laplace, Paris, France, 197 pp.
, and M. Imbard, 1996: A global ocean mesh to overcome the North Pole singularity. Climate Dyn., 12, 381-388.

Maltrud, M. E., and J. McClean, 2005: An eddy resolving global 1/10 deg ocean simulation. Ocean Modell., 8, 31-54.

Matsumoto, K., and Coauthors, 2004: A fifty-year eddy-resolving simulation of the World Ocean: Preliminary outcomes of OFES (OGCM for the Earth Simulator). J. Earth Simulator, 1, 35-56.

Nakamura, H., A. Nishina, H. Ichikawa, M. Nonaka, and H. Sasaki, 2008: Deep countercurrent beneath the Kuroshio in the Okinawa Trough. J. Geophys. Res., 113, C06030, doi:10.1029/ 2007JC004574.

Nauw, J., H. van Aken, J. Lutjeharms, W. de Ruijter, and A. Webb, 2008: Observations in the southern East Madagascar Current and Undercurrent system. J. Geophys. Res., 113, C08006, doi:10.1029/2007JC004639.

Peeters, F. J. C., R. Acheson, G.-J. A. Brummer, W. P. M. de Ruijter, G. G. Ganssen, R. R. Schneider, E. Ufkes, and D. Kroon, 2004: Vigorous exchange between Indian and Atlantic Ocean at the end of the last five glacial periods. Nature, 400, 661-665.

Roman, R., and J. Lutjeharms, 2007: Red Sea Intermediate Water at the Agulhas Current termination. Deep-Sea Res. I, 54, 1329-1340.

Schouten, M., W. de Ruijter, and P. van Leeuwen, 2002: Upstream control of Agulhas ring shedding. J. Geophys. Res., 107, 3109 , doi:10.1029/2001JC000804.

Siedler, G., M. Rouault, A. Biastoch, B. Backeberg, C. J. C. Reason, and J. R. E. Lutjeharms, 2009: Modes of the southern extension of the East Madagascar Current. J. Geophys. Res., 113, C01005, doi:10.1029/2008JC004921.

Skogen, M. D., 1999: A biophysical model for the Benguela upwelling system. S. Afr. J. Mar. Sci., 21, 235-249.

Steele, M., R. Morfley, and W. Ermold, 2001: PHC: A global ocean hydrography with a high-quality Arctic Ocean. J. Climate, 14, 2079-2087.

Swallow, J., and L. Worthington, 1961: An observation of a deep countercurrent in the western North Atlantic. Deep-Sea Res., 8, 1-19.

van Aken, H., H. Ridderinkhof, and W. de Ruijter, 2004: North Atlantic deep water in the south-western Indian Ocean. DeepSea Res. I, 51, 755-776.

van Leeuwen, P. J., W. P. M. de Ruijter, and J. R. E. Lutjeharms, 2000: Natal pulses and the formation of Agulhas rings. J. Geophys. Res., 105, 6425-6436.

Weijer, W., W. P. M. de Ruijter, H. A. Dijkstra, and P. J. Van Leeuwen, 1999: Impact of interbasin exchange on the Atlantic Overturning Circulation. J. Phys. Oceanogr., 29, 2266-2284.

Worthington, L., and H. Kawai, 1972: Comparison between deep sections across the Kuroshio and the Florida Current and Gulf Stream. Kuroshio-Physical Aspects of the Japan Current, H. Stommel and K. Yoshida, Eds., University of Washington Press, 371-385.

Zalesak, S. T., 1979: Fully multidimensional flux corrected transport algorithms for fluids. J. Comput. Phys., 31, 335-362. 